\title{
THE PERFORMANCE IMPLICATIONS OF TIMING OF ENTRY AND INVOLVEMENT IN MULTIPARTNER ALLIANCES
}

\author{
DOVEV LAVIE \\ Technion-Israel Institute of Technology and The University of Texas at Austin \\ CHRISTOPH LECHNER \\ University of St. Gallen \\ HARBIR SINGH \\ University of Pennsylvania
}

\begin{abstract}
We examined the distribution of benefits to partners in multipartner alliances by concentrating on dynamics of partner entry and involvement. Testing hypotheses in the Wi-Fi Alliance, we observed heterogeneity of benefits. In particular, the extent of organizational involvement in this alliance enhanced partners' reputation and market success with related product introductions but reduced their productivity. Participation in competing alliances enhanced productivity and market success despite potential efficiency losses. Finally, early alliance entrants gained market success, and both early and late entrants were more productive than intermediate entrants. These findings illuminate multipartner alliance complexity and disparity between common and private benefits.
\end{abstract}

In recent years, multipartner alliances have gained popularity, especially in technology-driven industries. A multipartner alliance is a collective, voluntary organizational association that interactively engages its multiple members in multilateral value chain activities, such as collaborative research, development, sourcing, production, or marketing of technologies, products, or services. Forms include R\&D consortia, official and de facto standard-setting or -promoting associations, multiparty production joint ventures, supplier networks, co-

We are grateful for the financial support received from the Mack Center for Technological Innovation at the Wharton School and the Alfred P. Sloan Foundation. We thank Pankaj Dinodia, Mike Hendron, Lydia Jones, Ekant Kohli, Nicola Malcherek, Joel Silverman, and Brett Smith for their research assistance, and also acknowledge the useful information received from our industry contacts: Shantam Biswas, Soumitra Das, Wayne Caswell, Jonathan Gaw, Frank Hanzlik, Paul Meche, Jens Milnikel, Liam Quinn, Kurt Scherf, and Phil Solis. An earlier version of this paper was presented at the 2004 Academy of Management Conference in New Orleans. The paper was also presented at the 2005 Association of University Professors of Management in Kiel, Germany, and the 2005 Strategic Management Society Conference in Orlando, Florida. Useful feedback was received from the associate editor Chet Miller and three anonymous $A M J$ reviewers as well as seminar participants at the University of Texas at Austin, the Technion, and the Interdisciplinary Center in Herzliya. marketing arrangements, and industry constellations. Addressing a related phenomenon, research on alliances, which has historically focused on the study of dyadic alliances, has expanded its investigation to networks composed of multiple dyadic alliances (Gulati, 1998; Gulati, Nohria, \& Zaheer, 2000; Hagedoorn, 1995; Osborn \& Hagedoorn, 1997; Powell, 1990; Uzzi, 1997). Researchers have highlighted the benefits that such alliance networks offer to partners and to their industries (Dyer \& Singh, 1998; Gulati et al., 2000; Powell, Koput, \& Smith-Doerr, 1996). However, a multipartner alliance is not a collection of independent dyadic alliances among a group of firms, nor can it be considered a network of partners that maintain direct ties to a single focal firm. Rather, the multipartner alliance setting entails multilateral interaction among partners and thus generates unique dynamics.

Prior research has suggested that in competition among multipartner alliances, one such alliance may outperform others (Gomes-Casseres, 1994; Lazzarini, 2007; Vanhaverbeke \& Noorderhaven, 2001). However, the idiosyncrasies of collaborative dynamics within multipartner alliances and their implications for individual partners are not fully understood. Partners strive to achieve the common objectives of their multipartner alliance but may differ with respect to their individual interests and compete for their shares of alliance benefits. The alliance literature has identified the benefits of al- 
liance networks and studied value appropriation in dyadic alliances (Gulati \& Wang, 2003; Khanna, Gulati, \& Nohria, 1998; Merchant \& Schendel, 2000), yet performance implications in multipartner alliances have remained largely underresearched. Do all partners benefit equally from their alliance affiliation? What factors explain the capacity of some partners to benefit more than others? Little is known about the heterogeneity of benefits to partners in multipartner alliances.

In this study, we introduce new ideas about the dynamics of multipartner alliances, seeking to explore how their unique aspects influence the differential benefits to partners. In particular, we focus on timing of entry and organizational involvement, as these factors distinguish multipartner alliances from dyadic alliances. Timing-ofentry issues are moot in dyadic alliances because, by definition, both partners' time of entry coincides with the time of alliance formation. By considering the timing of entry into multipartner alliances, we extend research on early mover and late mover advantages in an industry context (Lieberman \& Montgomery, 1988, 1998; Makadok, 1998). We further contribute by taking a dynamic approach that accounts for the realization of alliance benefits over the course of an alliance's life cycle rather than at a given point in time. We thus propose that the differing temporal logics of early and late entrants to multipartner alliances partially account for the heterogeneity of their benefits.

The internal involvement of partners in a multipartner alliance and their external involvement in competing multipartner alliances entail complex processes of managing multilateral relationships that elicit strategic behavior such as free riding, coalition building, and hedging. These dynamics are less apparent in dyadic alliances that maintain alignment between common and private benefits to partners (Khanna, 1998). Internal involvement refers to the extent to which partners engage in organizational activities of a focal multipartner alliance, whereas external involvement pertains to the extent to which these partners also participate in competing multipartner alliances. We challenge the conventional wisdom concerning the positive implications of extensive organizational involvement in alliances (Mothe \& Quelin, 2001) by revealing a trade-off between the market success and productivity gains of internally involved partners. In addition, we suggest that external involvement in competing multipartner alliances generates benefits that offset the efficiency losses from redundant investments.

We tested these ideas in the context of technology-driven industries using a unique database doc- umenting the evolution of the Wi-Fi Alliance ("WiFi" is an abbreviation for "wireless fidelity"). This multipartner alliance was formed in 1999 to certify the interoperability of WLAN (wireless local area network) products and promote their commercial use. By 2004, the Wi-Fi Alliance had established the IEEE 802.11 standard, introduced by the Institute of Electrical and Electronic Engineers, as the de facto industry standard, thus making it the dominant design in the WLAN industry and generating diverse benefits to the alliance's member partners. The Wi-Fi Alliance maintained voluntary entry and exit, attracting a large number of partners. Its governance structure was semidemocratic, comprising hierarchical layers of membership, each offering equal voting power to partners at that level. During the time frame of our study, this alliance faced technological and market uncertainty and competed against other multipartner alliances for dominance in its industry.

This study advances alliance research by investigating the performance implications of some unique aspects of multipartner alliances. First, by empirically revealing the implications of timing of entry, our study offers insights into aspects of alliance entry decisions that have been overlooked by prior research. Second, this study unpacks the organizational involvement effect by demonstrating the disparity between common benefits and private benefits due to extensive internal involvement and by accounting for follower advantage in multipartner alliances. Third, it extends prior work on competition between alliance constellations by highlighting the merits of simultaneous membership in competing multipartner alliances. Finally, this study extends prior research that has focused on the evaluation of post factum outcomes of alliances by analyzing the factors that explain the accrual of benefits to partners during the course of alliance evolution.

\section{THEORETICAL BACKGROUND}

Multipartner alliances have emerged in technology-driven industries in response to shortened product life cycles, increased demand for R\&D investments, need for product interoperability, and high levels of technical risk and market uncertainty. Under such conditions, a firm is less likely to succeed in independently developing, manufacturing, and marketing its proprietary solutions. Hence, in a technology-driven industry, a multipartner alliance operates as a voluntary arrangement among independent firms (partners) that exchange and share resources for the joint development and promotion of technologies. It typically 
assumes consensus-seeking democratic governance organization and thus differs from the traditional open-systems approach that a single sponsoring firm can lead. Partners in a multipartner alliance define and formalize needs and their technical solutions and, once a solution is formulated, they may test and certify products to ensure compliance, while promoting the adoption of the technology in the industry. A multipartner alliance enables member partners to collectively reduce costs and distribute risks while enhancing technological predictability (Eisenhardt \& Schoonhoven, 1996; Hagedoorn, 1993; Hagedoorn, Link, \& Vonortas, 2000; Powell et al., 1996; Sakakibara, 1997), thus driving technological innovation by means of collaboration rather than competition.

Despite the increasing popularity of multipartner alliances in recent years, research on this phenomenon is sparse (see Siegel [2003] for a review). Some emerging research has begun to examine the motivation for forming such alliances (Mitchell, Dussauge, \& Garrette, 2002; Yin \& Wu, 2003). Other studies have focused on R\&D consortia, noting that firms enter such consortia in high-margin oligopolistic industries and that their participation is further associated with their relative R\&D efforts and prior experience. Yet there is mixed evidence concerning the link between the appropriability regime of an industry and the formation of multipartner alliances (Sakakibara, 2001, 2002; Teece, 1986). Another stream of research has focused on the governance structure of multipartner alliances and analysis of their operations, studying practices and organization, decision-making processes, institutional intervention, and impediments to successful collaboration $^{1}$ (Besen \& Johnson, 1986; David \& Greenstein, 1989, 1990; Farrell \& Saloner, 1988; Rosenkopf, Metiu, \& George, 2001; Tushman \& Rosenkopf, 1992). This research sheds light on some of the potential benefits available to partners in multipartner alliances, which include access to technical and market information; networking and investment opportunities emerging from the pooling of partners' R\&D, engineering, and marketing

\footnotetext{
${ }^{1}$ In addition, economics research has focused on network externalities, lock-in effects, path dependence, information asymmetries, coordination challenges, compatibility, and pricing strategies, which influence the adoption of industry standards (Farrell \& Saloner, 1985, 1986a, 1986b; Katz \& Shapiro, 1985, 1986; Shapiro \& Varian, 1998). However, economics has primarily dealt with the motivation for joining multipartner alliances and the overall social benefits accrued through the use of a standardized product rather than with differential benefits to partners.
}

resources; and influence over evolution of industry standards (Rosenkopf et al., 2001). Additional benefits may include enhanced market visibility and legitimacy as well as coordination of partners' strategic industry moves.

Prior research also revealed that participation in R\&D consortia contributes to knowledge sharing and R\&D spending as well as to the R\&D productivity of partners, thus enhancing overall economic welfare (Sakakibara, 2003; Sakakibara \& Branstetter, 2003). However, in most cases, researchers have assumed these potential benefits to be available to all partners without studying differences in the capacity of partners to realize them. In the few cases in which researchers have studied how multipartner alliances enable partners to generate private benefits such as patents, the findings have been inconclusive: "What kind of firm receives the most substantial boost from participation? This is not a simple matter, and we have only begun to investigate the issue. ... It is difficult to come to any definitive conclusions about the role of size or overall R\&D spending in effecting research outcomes" (Sakakibara \& Branstetter, 2003: 64-65). Thus, extant research has not been able to fully account for the distribution of benefits among partners in multipartner alliances. Even the strategic alliance literature that has examined differential benefits to partners (Khanna et al., 1998; Koh \& Venkatraman, 1991; McConnell \& Nantell, 1985; Park \& Kim, 1997; Reuer \& Koza, 2000) has concentrated on dyadic alliances and ex ante measures of stock market returns to alliance announcements. Compared to dyadic alliances, multipartner alliances entail multilateral interaction among partners, a much more complex governance structure, and distinctive dynamics of collaboration. Hence, assuming that multipartner alliances are successful in achieving their objectives and generating benefits, the following questions remain open: (1) Can partners enjoy differential benefits in multipartner alliances? (2) What factors explain the distribution of benefits among partners in multipartner alliances?

Several scholars have acknowledged the conceptual distinction between the common benefits shared by all partners participating in an alliance and the private benefits gained by individual partners (Gomes-Casseres, 1994; Khanna et al., 1998), yet the heterogeneity of partners' private benefits has remained underresearched. Recently, Lazzarini (2007) showed that in the airline industry, the overall size of a formal alliance constellation and the relative size of a partner within that constellation contribute to the partner's operational performance, which also depends on the partner's infor- 
mal ties to other dominant partners. By examining the unique aspects of multipartner alliances, highlighting the role of external and internal involvement in them, and exploring the impact of the timing of partner entry into them, we extend this stream of research and offer new insights into the heterogeneity of partners' benefits in multipartner alliances.

\section{HYPOTHESES}

\section{Internal Involvement in Multipartner Alliances}

Partners differ with respect to their levels of internal organizational involvement in multipartner alliances. ${ }^{2}$ They can become involved in exchange of information, negotiation and evaluation of proposals, design and certification of new products, and monitoring of partner compliance with alliance decisions (Farrell \& Saloner, 1988). Frequently, these activities are tied to the type of alliance membership, which specifies the privileges and obligations of partners. For example, certain types of alliance membership offer the right to propose new projects or bestow stronger voting power, which allows some partners to engage more intensively in these activities.

Nevertheless, internal involvement also entails certain costs, such as increased membership dues and funding requirements, commitment of dedicated personnel, and allocation of managerial resources to the board of directors and committees of a multipartner alliance. In addition, a partner's efforts to steer a multipartner alliance in a desirable direction may attenuate the partner's absorptive capacity and receptivity to external knowledge, resulting in the neglect of collaborative learning opportunities that may emerge in the multipartner alliance. Finally, the partner may run into an impasse as a result of disagreements with other overinvolved, self-interested partners. However, according to organizational dynamics and social embeddedness theories (Granovetter, 1985; Pfeffer \& Salancik, 1978; Rowlinson, 2001), a multipartner alliance can adopt a governance structure that attenuates many of these drawbacks; for instance, it can restrict the number of board members or use democratic voting and conflict resolution procedures to reconcile partners' diverse interests. Part-

\footnotetext{
${ }^{2}$ We distinguish between deciding whether or not to join an alliance and the extent of organizational involvement in the alliance, which may differ among partners. We focus on the implications of organizational involvement rather than on the motivation for joining a multipartner alliance.
}

ners may also expect that their internal involvement will increase the likelihood of achieving the multipartner alliance's objectives and that the benefits of the alliance will eventually offset the organizational costs of internal involvement. We thus argue that partners that demonstrate greater internal involvement in a multipartner alliance benefit from their ability to set the alliance agenda, align its objectives, control the decision-making process, access and influence the flow of information, and effectively exploit alliance resources.

First, partners that are more involved in the organization of a multipartner alliance can better shape its agenda (Dutton, 1995) by occupying leadership positions that allow them to exert stronger organizational influence and to pursue their individual interests (Rosenkopf et al., 2001). Their favorable positions enable them to propose initiatives that complement and build upon their capabilities, leverage and promote their knowledge, and thus enhance the success of their product development efforts (Rosenkopf et al., 2001). Additionally, through their active involvement in the decision-making bodies of the alliance, organizationally involved partners can exert stronger control over decision premises, processes, and outcomes, thus enhancing learning and assimilation of alliance-specific knowledge (Saxton, 1997). Consequently, internal involvement enables partners to learn from other partners and to align alliance objectives with their corporate objectives, thus steering decisions in directions that are compatible with their interests and garnering tangible and reputational benefits.

Second, internal involvement enables partners to establish superior access to technical and market information and gain insights into the skills and technological innovations of other partners. Internal involvement entails active engagement in alliance activities and greater interaction with other partners, thus contributing to embeddedness in a network of strong and weak ties (Chung, Singh, \& Lee, 2000; Granovetter, 1985). This embeddedness provides efficient access to and control over sources of fine-grained information and tacit knowledge (Rowley, Behrens, \& Krackhardt, 2000; Tsai \& Ghoshal, 1998; Uzzi, 1996), which produce alliance benefits to internally involved partners.

Finally, internal involvement entails greater commitment to the advancement of alliance objectives. Consequently, internally involved partners are likely to exert greater effort in exploring and exploiting alliance-related opportunities. Intensive exploration may enable these partners to generate more innovative applications based on jointly developed technologies and to build supporting pro- 
cess- and product-related routines and capabilities that increase the likelihood of successful commercialization. Committed partners are also less likely to encounter implementation gaps as a result of limited managerial attention (Ocasio, 1997), and they are thus more likely to succeed with product introductions to targeted markets. Hence, internal involvement enables partners to better allocate and employ alliance resources, which may account for heterogeneity of multipartner alliance benefits across partners.

Hypothesis 1. In technology-driven industries, the greater a partner's internal involvement in a multipartner alliance, the greater its benefits from membership in that alliance.

\section{External Involvement in Competing Multipartner Alliances}

Prior research has considered the role of internal involvement in multipartner alliances but has not examined the performance implications of partners' external involvement in competing multipartner alliances. The clustering of firms into industrywide alliance constellations that offer competing technologies, products, or services has been documented in the airline, automobile, mainframe, multimedia, and other industries (Gomes-Casseres, 1994; Gomes-Casseres \& Leonard-Barton, 1997; Lazzarini, 2007; Nohria \& Garcia-Pont, 1991). Still, prior research has studied competition between multipartner alliances under the assumption that these constellations entail exclusive membership. Hence, scholars have explored how one multipartner alliance can outperform its competition or which such alliance a firm should join (GomesCasseres, 1994). Although some researchers have acknowledged the participation of partners in competing alliances (Gimeno, 2005; Silverman \& Baum, 2002; Stuart, 1998), they have focused on networks composed of dyadic alliances. Here we consider the phenomenon of partners' membership in competing multipartner alliances and suggest that such external involvement affects partners' capacity to extract benefits from a focal alliance.

In technology-driven industries, membership in competing multipartner alliances entails redundant resource investments in R\&D and dispersal of corporate resources and attention over technologies. Since not all competing technologies eventually become dominant designs (Tushman \& Anderson, 1986), engagement in competing multipartner alliances may lead to efficiency losses. In addition, external involvement in competing alliances may lead to suspicion and mistrust among partners in a particular multipartner alliance because conflicts of interest emerge when partners seek to promote competing technologies. Nevertheless, multipartner alliances can use governance to attenuate such conflicts by, for example, requiring a certain level of commitment from new partners, restricting board membership to partners that meet certain requirements, or disciplining partners that violate their obligations. Hence, we expect conflicts will be dealt with effectively and the benefits of engaging in competing multipartner alliances will outweigh efficiency losses. These benefits derive from enhanced information access, complementarity, interoperability, hedging, and partnering experience.

First, membership in competing multipartner alliances provides a partner with the means not only to cope with technical risk and market uncertainty, but also to reduce such uncertainty by accessing relevant knowledge and information. A partner's capacity to benefit from affiliation in a given multipartner alliance may be constrained by its comprehension of the technology the alliance concerns and the partner's assessment of market prospects. By engaging in competing multipartner alliances, a partner may better grasp the technological challenges and their possible solutions. An externally involved partner is also better positioned to identify potential competitors and assess their strengths and weaknesses. Moreover, engagement in competing multipartner alliances may enhance a partner's understanding of customer needs and thus reduce uncertainty concerning the likely adoption of alternative technologies. In this sense, partners that engage in competing multipartner alliances serve as network boundary spanners that can overcome overembeddedness in a given alliance by extending ties to external partners that furnish information on market opportunities (Uzzi, 1997).

Second, external involvement in multipartner alliances may enable a partner to offer better products by "benchmarking" technologies, combining knowledge, and integrating "best-of-breed" solutions that originate from competing alliances. Despite incompatibility of their alternative technology architectures, competing multipartner alliances may offer complementary designs for peripheral components or services that can be combined with the core technology of a focal alliance and enhance that technology's value (Dyer \& Singh, 1998; Henderson \& Clark, 1990).

Third, besides these complementarity benefits, membership in competing multipartner alliances may also offer interoperability benefits. Under conditions of uncertainty, when a dominant design is yet to emerge in an industry (Tushman \& Anderson, 1986), a partner can gain by ensuring compatibility 
among multiple technologies. The availability of multisystem televisions, multizone DVDs, and multimode cellular phones compatible with TDMA (time division multiple access), GSM (global system for mobile communications), and CDMA (code division multiple access) technologies demonstrates the demand for interoperable products.

Fourth, membership in competing multipartner alliances may serve as a hedging strategy, since investments in alternative technologies can be considered real options whose value appreciates with the technological and market uncertainty that a partner faces (McGrath, 1997). In technologydriven industries, external involvement provides the partner with favorable exit options should a particular multipartner alliance fail to produce a dominant design or lose its dominance to a competing alliance. With the dissipation of uncertainty, the partner can further invest in sponsoring a competing technology, or abandon it. The real options assumption is that there is strategic value in increasing the number of opportunities and, in turn, the variance in a partner's technology portfolio. Even though investments in competing multipartner alliance may limit the resources a partner can devote to a focal multipartner alliance, these organizational costs are assumed to be lower than the expected payoffs of sponsoring a successful technology (McGrath \& Nerkar, 2004). Thus, external involvement in competing multipartner alliances hedges downside risk and increases potential benefits.

Finally, external involvement may contribute to a partner's relational capability, which evolves with its accumulated experience in recurrent alliances (Anand \& Khanna, 2000) and may help it extract alliance benefits (Kale, Dyer, \& Singh, 2002; Lorenzoni \& Lipparini, 1999). A relational capability extends the partner's absorptive capacity (Cohen \& Levinthal, 1990), thus enabling the efficient accumulation, assimilation, and application of knowledge gained in other alliances. It also facilitates collaboration with partners by fostering trustbuilding, knowledge-sharing, and conflict resolution routines (Dyer \& Singh, 1998; Kale, Singh, \& Perlmutter, 2000). Although prior research has focused on relational capabilities in recurrent dyadic alliances, such capabilities may also play a role in concurrent multipartner alliances, especially in view of the need to manage complex and simultaneous alliance relationships. Thus, experience accumulated through external involvement in multipartner alliances may provide unique alliance benefits.
Hypothesis 2. In technology-driven industries, a partner's external involvement in competing multipartner alliances increases its benefits from membership in a multipartner alliance.

\section{Timing of Entry into Multipartner Alliances}

Assuming that partners may join a multipartner alliance at various times during the alliance's life cycle, the timing of their entry can affect their expected benefits. The opportunities that a multipartner alliance offers to entrants at its outset may differ from those available to later entrants. Unfortunately, the alliance literature has largely overlooked the implications of timing of entry. It is quite possible that internal involvement effects have been confounded with unobserved timing effects, an issue that calls for the simultaneous consideration of organizational involvement and timing of entry. For the purposes of this study, we define the timing of alliance entry in terms of the order in which partners join a multipartner alliance. Early entry does not necessarily imply that only a short time has passed since alliance formation. Rather, here, it implies that the cumulative density function of alliance entry corresponds to a low percentile of the total set; that is, an entry is early when it occurred before the majority of partners entered the multipartner alliance. We first consider the benefits of early entry and then, the benefits of late entry.

In line with early mover advantage research (Lieberman \& Montgomery, 1988), early entry into a multipartner alliance provides advantages that derive from path dependence in alliance evolution, efficient governance, and longer lead time. First, early entry enables partners to influence the evolution of a multipartner alliance. Often, fundamental decisions that determine the alliance's organizational and technological progress are made early on. Path dependence may make these decisions resilient to subsequent change. For example, in multipartner alliances that advance industry standards, technical specifications are built upon formally defined standards to ensure interoperability (David \& Greenstein, 1990). The modularity of technological evolution leads to path dependence in alliance decisions. In general, early entry lays the groundwork for these path-dependent processes, allowing partners to promote decisions that build upon their own capabilities and prior R\&D efforts, thus requiring minimal adaptation and potentially enhancing product quality. Another type of path dependence is related to alliance formation decisions (Chung et al., 2000; Gulati, 1995b; Gulati \& Gargiulo, 1999). As additional partners join an alliance, early en- 
trants are more likely to occupy central positions in the networks of formal and informal ties to other partners. Such path dependence relates early entry to advantages in creating rich information channels and building internal coalitions.

Second, early entry provides advantages in forming and utilizing governance and coordination mechanisms in a multipartner alliance. It allows partners to establish the alliance governance mechanisms that best fit their interests. These mechanisms influence the evolution of the multipartner alliance and its outcomes by defining and monitoring the nature of collaboration among partners (Doz, 1996; Reuer, Zollo, \& Singh, 2002; Ring \& Van de Ven, 1994; Zollo, Reuer, \& Singh, 2002). Although partners can attempt to maximize their private benefits by devising governance mechanisms that restrict further entry into the alliance and discriminate against subsequent entrants (Khanna, 1998), such a practice may not be in the best interest of partners, whose common benefits depend on the attractiveness of the multipartner alliance to new entrants that can support it in competition against other such alliances. In addition, at an early stage of alliance evolution, the need for complex coordination mechanisms is low, since the number of partners is comparably small. This relative simplicity makes the behavior of partners more easily observable, thus improving the efficiency of alliance governance. Hence, at any given time, early entry economizes on the cumulative transaction costs associated with monitoring partners' behavior (Williamson, 1979).

Finally, early entry enables partners to pioneer the introduction of alliance-reliant products. This advantage is critical in industries characterized by frequent innovation and weak appropriability regimes that allow for spillover of intellectual property. In such industries, longer lead time provides early mover advantages, which typically erode with intensified competition (Huff \& Robinson, 1994; Makadok, 1998). Therefore, early entry to a multipartner alliance benefits partners by extending the lead time for their innovations and product applications. Overall, the path dependence, governance, and lead time benefits are expected to diminish as further entries take place and partners enter later in the alliance life cycle.

The benefits of early entry do not necessarily imply that early entrants outperform later entrants. Late entry also provides benefits to partners, albeit of a different nature. These benefits include avoidance of set-up costs, lower technological and market uncertainty, and more efficient exploitation of the accumulated knowledge of other partners. First, late entry enables partners to avoid set-up invest- ments that are necessary in the process of alliance formation. For example, a partner may avoid investments in the search for and negotiation with like-minded partners in the early stage of establishing a multipartner alliance, when objectives and organizational structure are being developed. More importantly, late entry reduces R\&D costs, which are typically higher in the exploratory stage of developing technologies. Late entry also limits investments in market education, since the most crucial technical and marketing decisions are typically made early in the multipartner alliance life cycle. Because late entry occurs at the exploitative stage of this life cycle (Hite \& Hesterly, 2001), it enhances a partner's ability to manage its engagement in the multipartner alliance and invest in the appropriation rather than in the creation of common benefits.

Second, late entry allows partners to consider which multipartner alliance to join on the basis of accumulated information about prior alliance performance. Hence, late entrants can decide to join an alliance that has already emerged as the winner of a competition among multipartner alliances to establish a dominant design. In this way, late entry can minimize investments in unproven or commercially unsuccessful technologies. Since the success of a multipartner alliance in achieving a dominant design may depend on the number of partners that develop alliance-reliant products (Katz \& Shapiro, 1986), the likelihood of failure decreases as entries increase. Therefore, late entry reduces technical risk and market uncertainty.

Finally, late entry enables partners to fully concentrate on the opportunities provided by an established alliance. Although pioneering firms may excel in technological invention, they do not necessarily also excel in product commercialization (Teece, 1986). The dynamics of competition change with the conclusion of an "era of ferment" in industry evolution (Tushman \& Anderson, 1986), at which point the emphasis shifts from product innovation to process innovation (Utterback, 1987). Thus, entrepreneurial orientation, which is desirable at the exploratory stage of technology development, becomes less critical than access to complementary assets in the exploitative stage of commercialization. In multipartner alliances, late entrants with complementary assets and managerial expertise can free ride on the efforts of incumbent partners. For instance, they can appropriate rents from products that utilize a technical solution developed by other partners without contributing to its specification. More generally, late entry to a multipartner alliance facilitates the use of accumulated alliance knowledge (Larsson, Bengtsson, Henriksson, \& Sparks, 1998) and thus can 
eliminate costly mistakes. It minimizes partners' investments and increases their expected benefits from exploiting alliance resources. Overall, the benefits associated with set-up cost avoidance, reduced uncertainty, and efficient exploitation accrue as partners enter later in the alliance life cycle.

Considering the potential benefits of both early and late entry, we conjecture a U-shaped relationship between a partner's timing of entry into a multipartner alliance and its benefits from alliance affiliation. The benefits of late entry do not cancel out those of early entry because benefits accumulate at different times to different groups of partners. ${ }^{3}$ As the alliance evolves, early entry benefits diminish in value, while late entry benefits increase in value. Consequently, either early or late entry is expected to produce greater benefits than intermediate entry.

Hypothesis 3. In technology-driven industries, the benefits from membership in a multipartner alliance are curvilinearly related to the timing of alliance entry, with early and late entry producing greater benefits than intermediate entry.

\section{METHODS}

\section{Research Setting: The Wi-Fi Alliance}

In selecting a setting for our study, we considered several criteria: (1) the context's appropriateness for our purposes, (2) the representativeness of the focal alliance, and (3) the accessibility and suitability of data for analysis. After searching press items on multipartner alliances and reviewing lists of technical associations, we selected the Wi-Fi Alliance as the subject of our inquiry. First, in terms of context appropriateness, we intended to examine a multipartner alliance in a technology-driven industry that competed against other multipartner alliances and produced benefits to its partners. The fact that the Wi-Fi Alliance competed in the emerging WLAN industry and was successful in establishing the IEEE 802.11 standard as the dominant design in this industry suggested that at least some

\footnotetext{
${ }^{3}$ Late entry benefits begin to accumulate only after certain conditions are met, such as the completion of set-up investments in alliance organization, technology development, and market education; the accessibility of jointly developed knowledge; and the resolution of market uncertainty. It would be inaccurate to assert that early entrants earn fewer benefits of this type, since at the early stage of alliance evolution the aforementioned conditions are yet to be met, making the late entry benefits inapplicable for these early entrants.
}

Wi-Fi partners were able to extract benefits from this alliance, allowing us to test our hypotheses. Second, the Wi-Fi Alliance was representative with respect to its activities and governance structure. It operated both technical and marketing committees, thus covering $\mathrm{R} \& \mathrm{D}$ and marketing activities. Additionally, its governance structure incorporated a sponsoring board, specialized democratic committees, and multiple layers of membership-all of which are typical in technology-driven industries. Finally, most other alliances had fewer members or offered limited archival information concerning membership, time of entry, and certified products. We identified 250 Wi-Fi Alliance member partners, a sufficient number for empirical analysis. This alliance has received extensive media coverage, and it offered abundant archival information for measuring the study's variables. It also constituted a well-defined network with clear boundaries, since any firm that sought to certify Wi-Fi products was required to join the alliance.

The Wi-Fi Alliance was formed in August 1999 to test and certify the interoperability of WLAN products based on the IEEE 802.11 standard. The founding partners were 3COM, Agere Systems, Cisco Systems, Intersil, Nokia Networks, and Symbol Technologies. As of June 2003, 194 Wi-Fi partners were listed, and about 800 products had been certified since certification began in March 2000. By January 2006, there were 224 listed partners, with over 2,200 certified products. Wi-Fi products embed a radio technology enabling wireless computer connectivity to the Internet and to wired networks. Certified Wi-Fi products include PCMCIA (Personal Computer Memory Card International Association) cards for notebooks, PCI (peripheral component interconnect) cards for desktop computers, USB (universal serial bus) modules, and wireless base stations with access points and gateways. These products enable users to send and receive data without connecting to a wired network, whether at home, at the office, on campus, or in an airport, hotel, coffee shop, or other public area. The Wi-Fi Alliance promotes this technology among manufacturers that use standardized technologies in their wireless networking products and markets it to customers in the home, office, and enterprise markets.

Membership in the Wi-Fi Alliance has been open to all firms with a business interest in the IEEE 802.11 standard and a willingness to support the alliance by enabling technology, shipping or deploying products, or promoting the standard. As of June 2003, annual fees were $\$ 25,000$ for general membership and $\$ 125,000$ for membership on the board, which comprised Agere Systems, Cisco Sys- 
tems, Dell, Intel, Intersil, Microsoft, Nokia, Philips, Sony, Symbol Technologies, and Texas Instruments at that time. Any decision approved by the general membership vote was subject to two-thirds majority approval by the board. Board members were better positioned to influence decisions about the allocation of marketing funds. They set the agenda for committees and exerted influence by interacting with regulators.

The Wi-Fi Alliance operated through two committees. The marketing committee promoted the visibility of certified Wi-Fi technologies and dealt with the promotion of standards $802.11 \mathrm{~g}$, $802.11 \mathrm{~h}+\mathrm{d}$, and $802.11 \mathrm{n}$, as well as with ease of use, connectivity, consumer electronics, coexistence, public access, quality of service, and security issues. The technical committee managed the interoperability certification program by revising the certification test matrix, resolving interoperability issues, and coordinating spectrum allocation by regulatory institutions. The Wi-Fi Alliance conducted testing and certification of Wi-Fi product interoperability in independent test labs. Upon successfully passing the test, partners were granted the Wi-Fi seal of approval and were given permission to display the Wi-Fi logo on their certified products. Besides the marketing value of product certification, Wi-Fi partners gained by accessing technical information, pooling resources and sharing marketing costs, promoting the interoperability of their technologies, avoiding royalty payments to other proprietary technology providers, and restricting the number of potential competitors. However, not all partners engaged in the certification of products. Whereas "active certifiers" developed new products, "noncertifiers" were mostly interested in the licensing and production of third-party products, in complementary infrastructure or service, or in integrated systems that embed Wi-Fi components. Noncertifiers benefited from the opportunity to evaluate the Wi-Fi technology and influence its future development and usage, while building a capacity for more active internal involvement in the future. Most importantly, they benefited by networking with technology providers and enjoying the reputation and marketing advantages associated with the Wi-Fi brand.

In its early days, the Wi-Fi Alliance faced competition from three competing multipartner alliances: HomeRF, Bluetooth, and HiperLAN. HomeRF supported a frequency-hopping technology that combined "streaming media" data capabilities with voice protocols of the European digital enhanced cordless telephone (DECT) standards. HomeRF, a proprietary technology of chip maker Proxim, was backed by Compaq, Intel, and Mo- torola. The Wi-Fi technology became more pervasive than HomeRF as a result of the cost advantages associated with an open standard. The HomeRF working group eventually dissolved in January 2003, after Intel defected to the Wi-Fi Alliance. The Bluetooth technology offered a short-term point-topoint alternative for transmitting voice and data between handheld devices and wired computers. It was supported by the Bluetooth Special Interest Group, which included about 4,000 adopters and 200 associate members, such as Nokia and Ericsson. The short range and low power of Bluetooth allowed for its incorporation in only a few commercial products, such as cellular phones, so this technology has not been widely adopted in the market. The HiperLAN alliance emerged in August 1996 with the approval of a competing standard that had been in development by the Radio Equipment and Systems Group 10 of ETSI (the European Telecommunications Standards Institute) since 1991. HiperLAN1 was backed by Apple Computer, Advanced RISC Machines, and GECPlessey Semiconductors. Although it was more technically advanced than the IEEE 802.11 standard, it was late to market and did not gain acceptance in the United States, a failure that allowed the IEEE 802.11 standard to dominate the market. The HiperLAN1 alliance was dissolved, but the HiperLAN2 Global Forum initiated by Bosch, Dell, Ericsson, Nokia, Telia, and Texas Instruments was able to release certified products in late 2002 (Wi-Fi products began shipping in early 2000.) As of June 2003, only 14 partners were listed in the HiperLAN alliance, leaving the IEEE 802.11 standard supported by the Wi-Fi Alliance as the de facto industry standard.

\section{Sample and Data}

Adopting the firm as the unit of analysis, our study focused on all the partners that joined the Wi-Fi Alliance between August 1999 (the time of alliance formation) and June 2003. This sample included 250 partners, for 227 of which we were able to establish the alliance entry date. We observed only 70 exits from the alliance during this period. These exits did not bias our results because we controlled for the duration of membership in productivity analyses.

We relied primarily on archival data sources, including detailed lists of Wi-Fi partners and their certified products, which we extracted from the corporate Web site of the Wi-Fi Alliance (www. wi-fi.org). Membership lists of the HiperLAN, HomeRF, and Bluetooth alliances were obtained from their respective Web sites or directly from their representatives. The Factiva database offered 
press releases, including periodical announcements of Wi-Fi membership and announcements of partners joining the Wi-Fi Alliance, which we used to establish the approximate date of entry into the alliance as well as to compute our market exposure measure. The U.S. Patent \& Trademark Office (USPTO) databases provided full-text access to issued patents and patent applications. We used these databases to determine whether partners patented Wi-Fi technologies and to assess their product diversity. The COMPUSTAT and Dun \& Bradstreet databases offered industry classification and financial data for public and private partners in our sample. We also issued a survey to industry experts in order to assess the market success of Wi-Fi partners. Finally, we relied on partners' corporate Web sites as well as on the databases Gartner Dataquest, Corporate Affiliations, Gale's Business \& Company Resource Center, and Mergent Online to crossvalidate and test the robustness of our measures.

We elaborated our research design via 12 personal interviews conducted with the managing director of the Wi-Fi Alliance, the vice chairman of its board of directors, industry analysts, directors of competing alliances, executives of partners participating in the Wi-Fi Alliance, and representatives of its committees. The qualitative analysis of interview transcripts enabled us to gain insights into the causal mechanisms that drive our empirical results and assisted in the interpretation of our findings.

\section{Dependent Variables: Alliance Benefits}

Multipartner alliances in technology-driven industries offer various benefits to partners with respect to both their product development and marketing efforts. To capture different aspects of alliance benefits, we considered three measuresproductivity, market success, and market exposure-as our dependent variables. These complementary measures range from a narrow focus on products to a wider focus on corporate benefits. We address their properties below.

Productivity. The multipartner alliance's contribution to the product development efforts of each partner was measured as the partner's number of certified products listed on the Wi-Fi Web site in June 2003, standardized by the duration of the partner's membership in the Wi-Fi Alliance. ${ }^{4}$ Our in-

\footnotetext{
${ }^{4}$ A partner's number of certified products may depend on the duration of its membership in the alliance. Thus, we standardized the product count by the number of days (reported in year units) in which a partner was a member in the Wi-Fi Alliance prior to June 2003. The
}

dustry experts and Wi-Fi representatives identified productivity as the most relevant, accessible, and objective quantitative measure of partners' success in the Wi-Fi certification program. Since by definition noncertifiers had no certified products, we performed the analysis by first incorporating all the partners and then repeating the procedure only for the subsample of active certifiers. Noncertifiers were excluded from the latter analysis because the benefits that they extracted from the multipartner alliance could not be captured by this productivity measure.

Market success. The number of certified products does not capture product quality or customer acceptance, nor does it reflect the success of channel partners that market third-party products; as a Wi-Fi board member whom we interviewed noted, "Our measure of success is, Does going to the Wi-Fi alliance and getting certified help improve the probability that our customers are going to be delighted with the Wi-Fi aspects of our products?” To capture the extent to which partners succeeded with the products that they introduced or marketed in the Wi-Fi market, in September 2004 we invited a panel of industry experts to rate each of the 250 partners, including noncertifiers that offered Wi-Firelated products and services. Our guidelines to the experts were as follows: "Please rate the market success that the following Wi-Fi members gained with the development, introduction, and marketing of products based on the IEEE 802.11 standard." Our four industry experts were the former marketing chairman of HomeRF, a vice president and principal analyst at Parks Associates, a senior analyst at ABI Research, and a research manager at IDC, all of whom specialized in the WLAN industry and were independent industry experts able to provide consistent and unbiased evaluations of all Wi-Fi partners. The industry experts independently rated each partner that they recognized on a 1-10 scale, with 10 representing the highest level of success. Partners not recognized by any expert were assigned a 0 . The market success measure was computed as the average score that the partner received from the four experts. Interrater reliability was high $(\alpha=.83$, eigenvalue $=2.68)$, and the measure was correlated with the product counts and market exposure measures $(r$ 's $=.41$ and .56 respectively, $p<.001$ ).

Market exposure. Multipartner alliances offer legitimacy and reputation benefits beyond those

duration of alliance membership was incorporated in the negative binomial regression model when productivity served as the dependent variable. 
directly related to products and services. To capture these broader benefits, we constructed a measure of market exposure based on the number of relevant press items (reported in thousands) mentioning a partner in connection with the Wi-Fi Alliance. To compute this measure, we counted the number of items extracted from Factiva between August 1999 (alliance formation) and September 2004 for full-article searches using the string, "[Partner name] AND [Wi-Fi OR WECA OR "Wireless LAN” OR WLAN OR IEEE802 OR “IEEE 802”] AND [product* OR technology OR offering OR market* OR develop]." This search string produced more relevant items than alternative strings, which incorporated different keywords, date ranges, and search fields. The selected measure was positively correlated with the nine market exposure measures produced with the alternative strings $(.63<r<.99$, $p<.001)$.

\section{Independent Variables}

Internal involvement. We measured level of internal involvement in the Wi-Fi Alliance with two different proxies. First, we used a measure of a partner's participation in the alliance board. Board membership entailed a larger financial investment in the alliance as well as stronger voting power and ability to influence resource allocation decisions and set the agenda for the alliance committees. Board members were more actively involved in lobbying activities with regulators and were more committed to the promotion of Wi-Fi technologies. Board membership was dummy-coded 1 if a partner was listed as a board member on the Wi-Fi Alliance Web site, and 0 otherwise.

Second, we distinguished between partners that actively engaged in the certification of Wi-Fi products (active certifiers) and those that did not develop Wi-Fi products, using a dummy variable coded 1 if a partner had certified products listed on the Wi-Fi Web site. To avoid misclassifying partners that initiated product development as noncertifiers, we considered products that were certified between March 2000 (when certification began) and September 2004. Of the 250 partners, 137 were active certifiers, and the remaining 113 were noncertifiers. Active certifiers were more organizationally involved in the alliance than noncertifiers by virtue of their larger stakes in Wi-Fi technologies. They could submit technical proposals to the alliance's committees and promote their technologies within the alliance. This measure was incorporated as an independent variable in the analysis of market success and market exposure.
We also studied the productivity of active certifiers by repeating the productivity analysis for the subsample of active certifiers. Both internal involvement measures were used in testing Hypothesis 1.

External involvement. We measured the external involvement of Wi-Fi partners in competing multipartner alliances in the WLAN industry by including a count variable that indicated the number of competing alliances (HiperLAN, HomeRF, or Bluetooth) in which a partner participated at any time between August 1999 (alliance formation) and June 2003. The HiperLAN and Bluetooth Web sites offered membership lists, and the former marketing chairman of HomeRF provided a list of members in his alliance (the HomeRF Web site was shut down after that alliance was terminated). To corroborate our data and account for unlisted partners that had exited these alliances, we also searched Factiva for announcements of membership in the three competing alliances. We found that 26 percent of the partners in the Wi-Fi Alliance had engaged in competing alliances; 63 percent of this subset had been in one competing alliance; 26 percent, in two; and 11 percent, in all three. The order of entry into competing alliances was typically sequential and in 85 percent of the cases was also consistent with the order in which these alliances were formed. Most remaining cases were founding members that chose to take part in forming a new alliance instead of joining an existing one. The external involvement measure was used in testing Hypothesis 2.

Timing of entry. To test Hypothesis 3, we measured a partner's timing of entry on the basis of all partners' order of entry. We sorted partners by date of entry into the Wi-Fi Alliance and then calculated their order of entry. Partners with the same recorded entry date received identical scores, so that the resulting variable had only 38 unique levels. We treated timing of entry as a continuous variable in our analysis. We based approximate date of entry on press items in Factiva and the Wi-Fi Alliance Web site's press release section. In most cases, we were able to corroborate the entry date with at least two data sources. In some cases, however, we found only general press releases issued by the Wi-Fi Alliance, announcing the addition of several new partners in a given month. In these cases, we corroborated the approximate date of entry based on these periodically issued lists of partners, searching for the first list mentioning a partner. These techniques generated entry date data for 210 partners. We contacted representatives of the remaining 40 partners, of which 17 were able to provide us with the missing data about their firms' 
entry dates. In total, the approximate entry date was available for 227 of the 250 partners. ${ }^{5}$

\section{Control Variables}

Density of entry. Since in some cases we were only able to estimate the approximate date of alliance entry, we controlled for the number of Wi-Fi partners that posted alliance entry announcements in the same month as the partner in question.

Industry classification. The industry classification of partners can be related to their alliance benefits, since the technological challenges and $\mathrm{R} \& \mathrm{D}$ and marketing efforts of firms may vary across industries. Industry classification was measured as the two-digit primary SIC code of partners in the Wi-Fi Alliance. This measure was available for 213 of the 250 partners in our sample. As indicated in Appendix A, most of the partners operated in the electronics (SIC 36, 37\%), computer equipment (SIC 35, 23\%), software business services (SIC 73, $17 \%$ ), equipment wholesale (SIC 50, 12.5\%), and communications (SIC 48, 6.5\%) industry segments. To avoid complete determination of the dependent variable in regressions, we consolidated the industry classification variable by creating dummies for the five aforementioned industry segments and grouping the remaining industry segments (which had fewer than 5 observations each and 21 observations in total) with the nonavailable data category (37 observations). ${ }^{6}$

Product diversity. Development and marketing of certified Wi-Fi products might be easier in some product categories than in others. Appendix A depicts the overall number of certified Wi-Fi products by the following categories: application-specific

\footnotetext{
${ }^{5}$ Determination of timing of entry can be made only ex post, when the pattern of entry has stabilized. Otherwise, late entrants at time $T$ might be considered early entrants at time $T+t$. In the case of the Wi-Fi Alliance, the number of partners had remained pretty stable since 2003, the year in which we measured order of entry. Although partners cannot accurately determine their relative timing of entry when they join a multipartner alliance, they can assess it by relying on clues such as the stage of technology development, assessments of prior entrants' investments, the level of market uncertainty, the rate of product adoption, and the proportion of competitors that have already joined the alliance.

${ }^{6}$ Similar findings were obtained when the remaining industry segments were not combined with the nonavailable data category. One of the objectives of consolidating the the industry classification variable was to minimize the loss of degrees of freedom and reduction in sample size.
}

devices, Ethernet client adapters, wireless print servers, compact flash components, USB client adapters, external PC cards, internal PC cards, and access points. Partners that offered various Wi-Fi products rather than focusing on a single type of product demonstrated proficiency in Wi-Fi technologies and were expected to increase their alliance benefits as a result of economies of scope. The product diversity of a partner was measured as $1-\Sigma_{j} k_{i j}^{2} / N_{i}^{2}$, where $k_{i j}$ was the number of products certified by partner $i$ in category $j$, and $N_{i}$ was the partner's total number of certified products. High values of this measure indicated greater product diversity.

Innovativeness. We controlled for a partner's innovativeness, since alliance benefits may be related to the partner's private innovation capacity rather than to its involvement in the Wi-Fi Alliance. Innovativeness was measured as the number of patents mentioning variations of the term "wireless LAN" that had been issued to or applied for by a partner during the period August 1999 through June 2003, which preceded, in most part, the measurement of our dependent variables. To construct this measure, we reviewed the description of the patents and patent applications in the USPTO databases to ensure that the identified patents were indeed related to WLAN technologies. Our selected measure was preferred to more general measures of patent counts or R\&D intensity that might not reflect firms' innovative capacity in the technological domain of the WLAN industry. ${ }^{7}$

\section{Analysis}

Table 1 reports descriptive statistics. The analysis was carried out separately for each dependent variable. First, we ran hierarchical negative binomial regressions to test the effects of organizational involvement and timing of entry on productivity. Models 1a-5a in Table 2 give the regression results for the complete sample of Wi-Fi partners, and models 6-10 in Table 2 give these results for the subsample of active certifiers. By definition, all noncertifiers had zero productivity, so to avoid complete determination of the dependent variable, we did not incorporate the active certifier measure

\footnotetext{
${ }^{7}$ Innovativeness, as captured by related patent counts, could not serve as a proxy for alliance benefits in this study because the openness of the IEEE 802.11 standard and the collaborative specification efforts of the Wi-Fi Alliance preclude the claiming of related patents by any individual partner. In fact, when joining the Wi-Fi Alliance, partners are required to disclose related patents and grant a royalty-free license to the alliance.
} 
TABLE 1

Descriptive Statistics $^{\mathbf{a}}$

\begin{tabular}{|c|c|c|c|c|c|c|c|c|c|c|c|c|c|}
\hline Variable & $n$ & Mean & s.d. & 1 & 2 & 3 & 4 & 5 & 6 & 7 & 8 & 9 & 10 \\
\hline 1. Number of certified products & 250 & 2.75 & 7.05 & & & & & & & & & & \\
\hline 2. Market success & 250 & 2.24 & 2.53 & .41 & & & & & & & & & \\
\hline 3. Market exposure & 250 & 0.38 & 0.92 & .37 & .56 & & & & & & & & \\
\hline 4. Active certifier ${ }^{\mathrm{b}}$ & 250 & 0.55 & 0.50 & .36 & .36 & .23 & & & & & & & \\
\hline 5. Board member ${ }^{b}$ & 250 & 0.06 & 0.23 & .21 & .41 & .64 & .19 & & & & & & \\
\hline 6. External involvement & 250 & 0.38 & 0.74 & .31 & .49 & .50 & .28 & .37 & & & & & \\
\hline 7. Timing of entry & 227 & 19.22 & 9.18 & -.30 & -.43 & -.35 & -.06 & -.37 & -.39 & & & & \\
\hline 8. Duration of membership & 227 & 1.78 & 0.99 & .30 & .43 & .36 & .07 & .39 & .40 & -.99 & & & \\
\hline 9. Density of entry & 227 & 15.99 & 11.76 & -.15 & -.23 & -.20 & -.02 & -.17 & -.22 & .59 & -.60 & & \\
\hline 10. Product diversity & 250 & 0.16 & 0.27 & .52 & .38 & .32 & .54 & .31 & .29 & -.27 & .27 & -.14 & \\
\hline 11. Innovativeness & 250 & 3.12 & 10.52 & .32 & .34 & .53 & .22 & .34 & .50 & -.30 & .31 & -.15 & .25 \\
\hline
\end{tabular}

${ }^{\text {a }}$ Correlation coefficients larger than .13 in absolute value were significant at the 5 percent level.

${ }^{\mathrm{b}}$ Measure of internal involvement.

as an independent variable in the productivity analysis. The negative binomial model is a generalization of the Poisson model that adjusts for overdispersion occurring when the variance of the estimated number of events exceeds its mean. The negative binomial model, which corrects this problem by including a varying error term that captures the overdispersion effects, thus allowing for variation in partners' chances of certifying products, is appropriate when the dependent variable describes counts of events made during varying spans of time. Thus, the number of product certification events of partner $i\left(y_{i}\right)$ that occurred during its alliance membership $\left(t_{i}\right)$ was assumed to take the form: $\log \lambda_{i}=\log \left(t_{i}\right)+\beta_{0}+\beta_{1} X_{i 1}+\beta_{2} X_{i 2}+\ldots$ $+\beta_{m} X_{i m}+\sigma \varepsilon_{i}$, where $\lambda_{i}$ is the expected value, $\exp \left(\varepsilon_{i}\right)$ is gamma-distributed, and $\sigma^{2}$ is a dispersion parameter (Barron, 1992). We implemented this model using maximum-likelihood estimation with duration of membership serving as the offset variable (Allison, 1999). Next, we ran models 1-5 using ordinary least squares (OLS) regressions with market success and market exposure serving as the dependent variables and active certifier incorporated as an independent variable. Table 3 presents these regression results. Missing values were treated with listwise deletion in all models. Hypothesis testing was based on the full model (model 5), which we compared to the baseline (model 1) to determine improvement in model fit. Besides using time lags between our dependent and independent variables, we report interview data in a separate section below to explore causal processes and enrich the interpretation of our empirical results.

\section{RESULTS}

The results of the baseline model reported in Tables 2-3 indicate that the density of entry was positively associated with productivity $(\beta=0.02, p$ $<.05$ ) and negatively associated with market success $(\beta=-0.04, p<.01)$, but these effects faded away in the full model (model 5). Significant interindustry differences were found, with higher productivity observed in the computer equipment $(\beta=$ 1.04, $p<.01)$, electronics $(\beta=0.82, p<.01)$, wholesale $(\beta=1.03, p<.01)$, and business services industry segments $(\beta=0.74, p<.05)$, but the latter effect became only marginally significant in the full model. In addition, higher market success was found in the computer equipment $(\beta=1.24, p<$ $.05)$ and electronics segments $(\beta=1.38, p<.01)$. Model 1 indicates that the product diversity of partners was positively associated with productivity $(\beta=3.76, p<.001)$, market success $(\beta=2.37$, $p<.001)$, and market exposure $(\beta=0.58, p<.001)$ and had persistent effects on productivity (Table 2 , model 5a). This positive effect suggests that partners may enjoy the complementarities, economies of scope, and growth prospects associated with related diversification (Rumelt, 1974). Our interviewees also suggested that customers favored partners that could offer a broad range of Wi-Fi products and solutions to ensure interoperability at the system level. Hence, partners that developed a variety of Wi-Fi products benefited more than partners that focused on narrow product lines. Similarly, the innovativeness of partners produced positive effects on productivity $(\beta=0.02, p<.05)$, market success $(\beta=0.06, p<.001)$, and market exposure ( $\beta=0.04, p<.001)$, with the latter effect remaining significant in the full model. These findings suggest that partners that patented innovative product designs were able to gain greater market recognition.

Hypothesis 1 was tested by examining the coefficients of the internal involvement variables in the full model. According to Table 2 (model 5a), board membership negatively affected productivity $(\beta=$ 


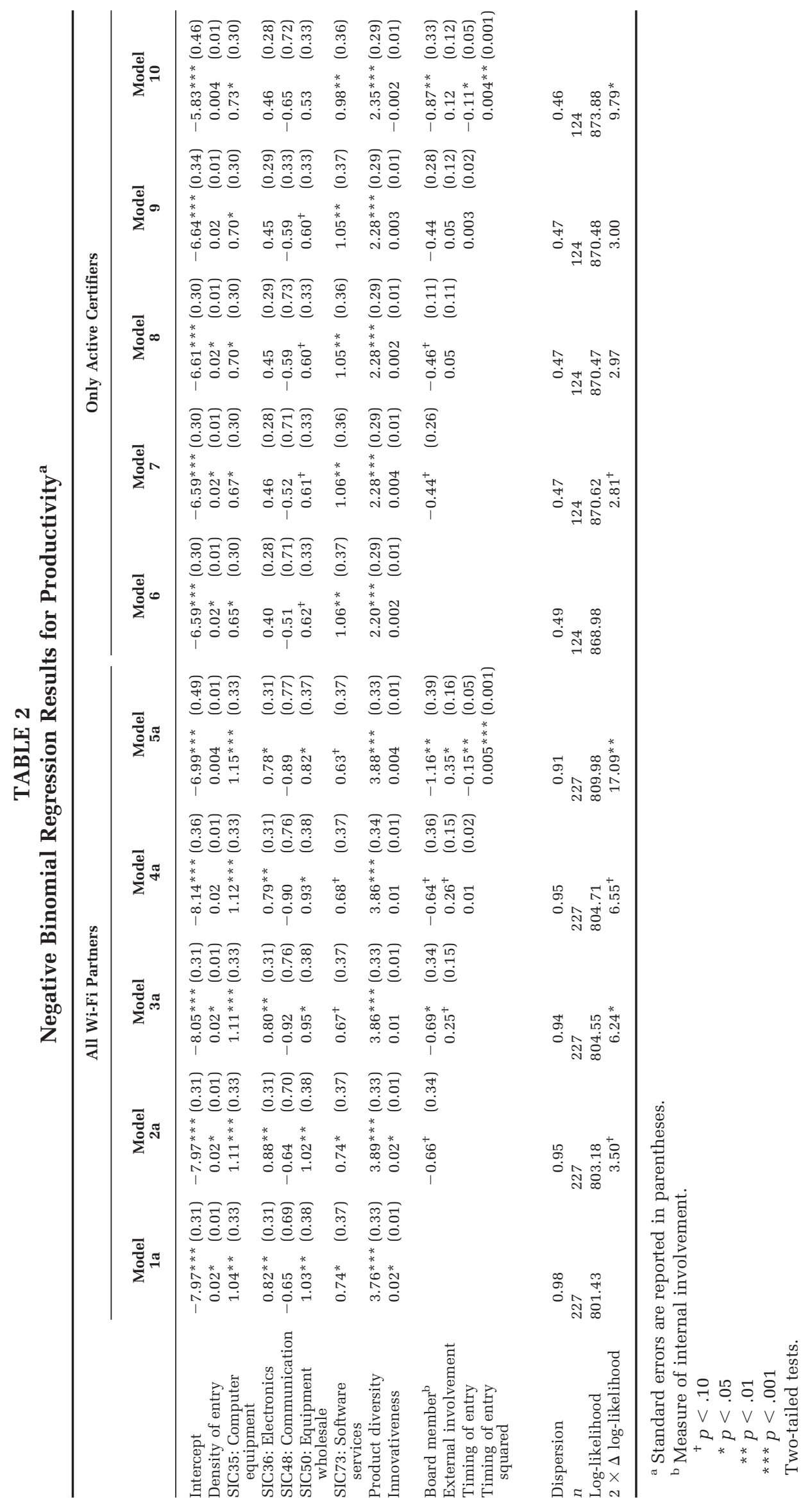




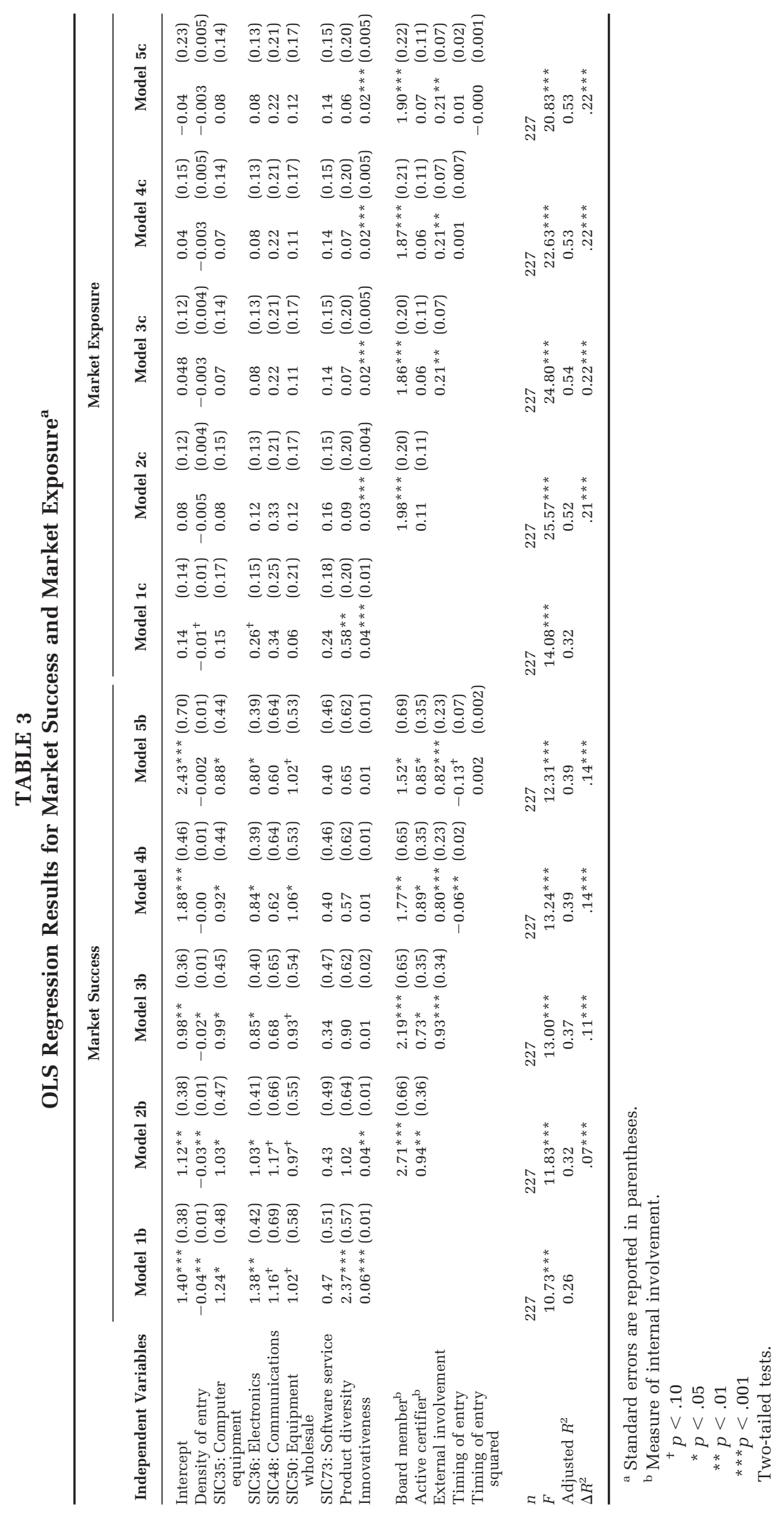


$-1.16, p<.01)$. This negative effect persisted in the subsample of active certifiers (model 10). Thus, contrary to Hypothesis 1, internal involvement through board membership negatively affected the productivity of Wi-Fi Alliance partners. Still, in support of Hypothesis 1, internal involvement produced positive effects on market success and market exposure (Table 3). In particular, according to model $2 \mathrm{~b}$, board members and active certifiers gained greater market success $(\beta=2.71, p<.001$, and $\beta=0.94, p<.01$, respectively), with these effects remaining significant in the full model (model 5b). In model 5c, board members also gained greater market exposure $(\beta=1.90, p<$ .001). Thus, Hypothesis 1 is supported with respect to market success and market exposure but not with respect to productivity.

Hypothesis 2 is supported by the data, as evidenced by the positive effects of external involvement in competing alliances on productivity $(\beta=$ $0.35, p<.05)$, market success $(\beta=0.82, p<.001)$, and market exposure $(\beta=0.21, p<.01)$. Finally, we tested Hypothesis 3 by introducing the linear and quadratic terms of timing of entry in model 5. In support of Hypothesis 3, the main effect of timing of entry on productivity was negative $(\beta=$ $-0.15, p<.01$ ), and the squared term was positive ( $\beta=0.005, p<.001)$, suggesting a U-shaped curve characterizing the impact of the timing of entry on the productivity of partners in the Wi-Fi Alliance (see Table 2). Timing-of-entry effects persisted in the subsample of active certifiers (model 10), with external involvement producing an insignificant effect, probably because of the severe reduction in sample size. Figure 1 depicts the timing-of-entry curve, revealing a minimum productivity level at the 34th percentile, which corresponds to one year and seven months after alliance formation. Thus, early and late entry resulted in higher productivity than intermediate entry, but late entry was compensated more than early entry, as indicated by the higher productivity late entrants achieved. ${ }^{8}$ Still, Table 3 shows that timing of entry produced a negative linear effect on market success in model $4 \mathrm{~b}(\beta=-0.06, p<.01)$ and no effect on market exposure in model 4c. No evidence of a curvilinear

\footnotetext{
${ }^{8}$ To validate the U-shaped pattern of the timing-ofentry effect, we conducted subsample analyses based on model 9 for the left-hand side and the right-hand side of the curve (splitting active certifiers into those that entered either before or after the 16th entry order). Consistently with our prediction, the timing of entry coefficient was negative on the left-hand side of the productivity function $(\beta=-0.12, p<.10)$ and positive $(\beta=0.06, p<$ $.05)$ on the right-hand side.
}

FIGURE 1 The U-Shaped Effect of Timing of Entry on Productivity $^{\mathrm{a}}$

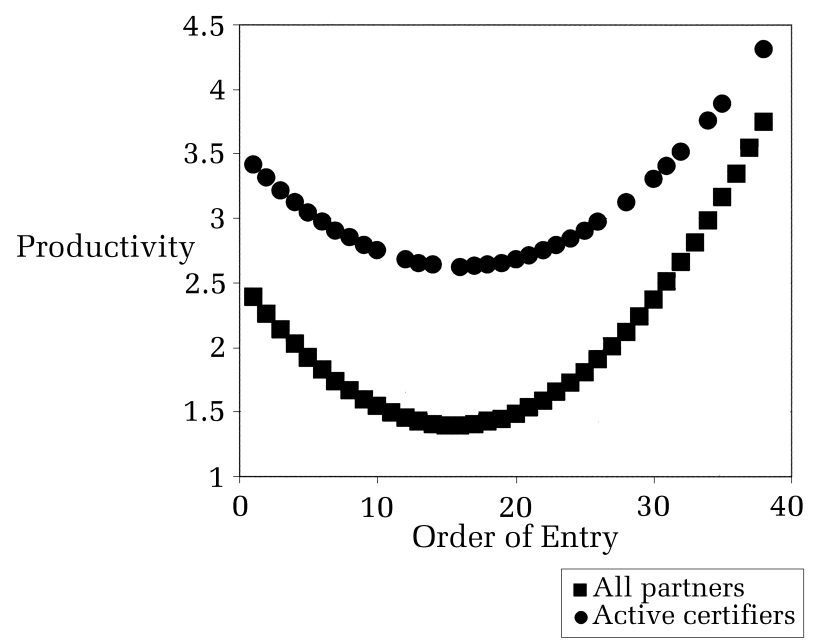

${ }^{a}$ Data for the complete sample are based on model 5a and data for the active certifiers are based on model 10. Timing of entry was measured as the order in which a partner or a group of partners entered the alliance. Productivity was measured as the predicted number of certified Wi-Fi products per year of membership in the alliance. For both the complete sample and the active certifiers subsample, minimum productivity is at the 16th entry order, which corresponds to the 78th entrant out of the total of 227 partners with recorded entry dates. Therefore, minimum productivity occurred at 34 percent entry.

timing of entry effect was found in the case of market success (see models $5 \mathrm{~b}$ and $5 \mathrm{c}$ ). Appendix B reports the results of robustness tests.

\section{FOLLOW-UP INTERVIEWS}

Following our quantitative analysis, we interviewed representatives of the Wi-Fi Alliance to gain further insights into the causal mechanisms that drove our results, focusing on the implications of organizational involvement and timing-of-entry decisions. We provide brief excerpts from these interviews below. Our presentation of a small but representative portion of interviewee comments adds important context to our study.

The interviewees suggested, for example, that entry and involvement decisions were made under conditions of uncertainty that limited the capacity of partners to estimate their expected alliance benefits:

There was lots of doubt about what wireless LAN if any would be successful. There was uncertainty about the prospects. From the perspective of a cellular phone supplier, the question was-here comes $3 \mathrm{G}$, why do you need wireless LAN? HiperLAN was in discussion in those days. There was also the 
Bluetooth scenario, whether Bluetooth or Wi-Fi would go out.

To cope with this uncertainty some partners intensified their internal organizational involvement in the Wi-Fi Alliance, despite the absence of immediate private benefits:

Believing that the technology had some merits, Nokia and some other companies had to solve these interoperability problems. The activity did provide the mechanism by which companies could come together and decide on how they have to be resolved. There is a significant difference in the financial support that board members give relative to the general membership. The board members pay a much heavier burden in keeping the Wi-Fi Alliance running. Board membership requires much more commitment . . p providing dedicated resources. It comes down to the belief in building the Wi-Fi ecosystem. If we build the largest ecosystem, then the competitive world will decide which companies get which slice of that pie, but everyone will be better off with a slice of a very large pie. All of the board companies have a genuine interest in the Wi-Fi ecosystem.

Interviewees also described how the Wi-Fi Alliance relied on democratic governance procedures to ensure that excessive internal involvement did not compromise its mission:

There is a healthy respect for each other and there is also a competitive element within the board. . . . It balances the needs of the industry. . . . Each member probably has vested interest in the IEEE 802.11 standard in a particular way of doing things. It is good that members have the ability to continue to push their ideas and advocate their point. There is an inherent check system within the Wi-Fi Alliance that requires certain critical mass for it to actually launch a program. ... At all levels there are voting procedures where you are trying to break the deadlock if there is one. The corporations prefer to have most of what they say uncontested but if that is not possible a voting takes place. ... At the end of the day there is a more robust solution that evolves from that activity.

Similarly, external involvement in competing multipartner alliances was considered beneficial:

We are members of a number of alliances, which does not preclude us at all from participation in the Wi-Fi Alliance. It brings in a lot of positives because you certainly are aware of different industries and segments.... You can bring best practices from each trade association and leverage relationships. ... Y You can get benefits from this cross-pollination. It can create appearances of conflicts of interest, . . . especially if the company is a board member because a sponsor member has an obligation to pro- mote this particular technology as the Wireless LAN technology in that frequency band. But, technology associations are full of this type of potential conflicts. At least at the general member level there is no issue here if you want to be a member of both.

Finally, interviewees revealed how the nature of alliance benefits varied with timing of entry:

If we look at the earlier entrants, they might be companies that look at things more futuristically . . . perhaps the companies with a longer strategic horizon. Then those companies with a shorter strategic horizon might become more involved when it becomes more obvious that it is going to go somewhere and it is going to be a success and they want to get in or they can now afford to get in. ... So the early adopters are either betting heavily on their R\&D and making it happen or have a view that it is something that needs to be monitored. And then the guys that come late tend to be opportunistic. ... Some companies have joined recently because they are in the business of certifying products. ... Because if you were developing networking products and you discover that the way to get more business from Sony or Dell is to certify your products ... to get into this space, this is the organization that you need to be part of. Whereas, initially it was more of a visionary orientation: how do we grow this business? The more companies see value in certifying and have access to the certification programs, the better.

\section{DISCUSSION AND CONCLUSIONS}

This study investigates the heterogeneity of alliance benefits among partners in a multipartner alliance. It complements prior research on competition between alliance constellations (GomesCasseres, 1994) by considering the competitive implications within such an alliance. Our focus shifts attention from the question of which alliance a firm should join to questions of when it should enter and how involved it should become in the alliance organization. With few exceptions (e.g., Lazzarini, 2007), prior research has focused on either private benefits in dyadic alliances or common benefits that multipartner alliances offer. Our findings reveal heterogeneity in the distribution of common and private benefits in a multipartner alliance. We demonstrate that some partners can benefit more than others, even though their alliance as a whole may emerge as a winner in technologydriven competition. This heterogeneity depends in part on partners' timing of entry as well as on the nature of their internal and external involvement in the alliance. 


\section{The Implications of Timing of Entry into Multipartner Alliances}

Our findings contribute to emerging research on alliance dynamics by highlighting temporal aspects of alliance entry decisions. Prior research on the evolution of networks composed of dyadic alliances has shown how firms' patterns of prior alliance ties guide alliance formation (Chung et al., 2000; Gulati, 1995b; Gulati \& Gargiulo, 1999). More recent research has described how alliance networks can substantially change over time and how these changes affect the benefits to partners (Dyer \& Nobeoka, 2000; Jensen \& Wang, 2003; Lavie, 2004). We contribute to this stream of research by exploring the performance implications of the timing of entry into multipartner alliances.

Our findings demonstrate how alliance entry timing may influence the productivity and market success of partners. Early entry enhances the success of partners in the development, introduction, and marketing of alliance-related products. This finding is partially consistent with research on early mover advantage (Lieberman \& Montgomery, 1988) that shows how firms that introduce pioneering products capture favorable market positions and gain customer acceptance, especially under conditions of uncertainty in technology-driven industries. However, whereas early mover advantage entails preemption and exclusive access to resources in an industry context, multipartner alliances make collective resources openly available to all partners, and thus they underscore appropriation rather than preemption of resources. Furthermore, our findings reveal that late entry into a multipartner alliance contributes to the productivity of partners as much as early entry, with lower productivity observed during the intermediate stage of alliance evolution. These findings highlight the disparity in the temporal logic of partners seeking to gain from alliance affiliation. Early entrants into a multipartner alliance can exert greater influence on alliance evolution, thus ensuring a better fit with their corporate strategies and objectives. They can also enjoy a pioneer image and limit the sharing of alliance benefits to a relatively small number of partners. In contrast, late entrants can reduce their technical risk and market uncertainty, and economize on their investments while accessing the technical information and knowledge of an established organization. Whereas early entry is associated with exploration of new opportunities, late entry supports exploitation of accumulated alliance resources (Lavie \& Rosenkopf, 2006). Hence, late entry creates efficiency gains in product development but does not carry the reputational appeal that the market associates with early entry, which accounts for the disparity in the timing-of-entry effects between productivity and market success.

Our findings shed new light on the dynamics of learning in alliances (Khanna et al., 1998; Larsson et al., 1998) by suggesting that the extent to which partners learn and their mode of learning in alliances (e.g., exploration versus exploitation) may be related to their independent decisions about the timing of entry rather than to relational aspects such as relative absorptive capacity, which researchers have considered as mechanisms that facilitate interorganizational learning (Hamel, 1991; Lane, Salk, \& Lyles, 2001). Hence, our dynamic approach acknowledges disparate logics of appropriation in multipartner alliances and links timing of entry to the benefits that partners extract from such alliances.

\section{The Implications of Internal Involvement in Multipartner Alliances}

Our study offers unique insights into the benefits of organizational involvement in multipartner alliances by revealing how the performance implications of internal involvement are contingent on type of alliance benefits. Following prior work (Mothe \& Quelin, 2001; Rosenkopf et al., 2001) and supporting our prediction, internal involvement in the alliance studied here contributed to partners' success with the introduction and marketing of their products and, in particular, enhanced the overall market visibility of board members. Quite surprisingly, however, we found that involvement in the board impaired productivity even when controlling for timing of entry and certification. Hence, such involvement in multipartner alliances provides external benefits related to partners' market reputations but comes at the expense of their individual product development efforts.

Internal involvement in multipartner alliances leads to market success since organizationally involved partners that join the board of an alliance or engage in product certification demonstrate genuine interest in and commitment to the activities and agenda of the multipartner alliance and thus gain more recognition in the market. Less involved partners, in turn, may consider alliance membership as a real option that provides them with the right to exit or become more involved in the future (Kogut \& Kulatilaka, 1993) but restricts their current marketing benefits. Internal involvement enables partners to more effectively access information and exploit alliance resources, to incorporate jointly developed technology, and to leverage the multipartner alliance's marketing investments. In partic- 
ular, board members can influence the agenda and decisions of alliance committees, allocate funds, and direct marketing efforts in order to enhance the perceived quality of their products and their consequent market acceptance. In addition, internal involvement in an alliance board enhances the market visibility of partners. Board members in a multipartner alliance serve as an interface between the alliance and external stakeholders such as government, community, and customers. By virtue of the board members' representative role, the media identifies them with the success of the alliance and provides them with a stage for promoting their corporate agendas. Unlike board membership, product certification does not entail superior market exposure, since both certifiers and noncertifiers enjoy visibility and reputation by virtue of their alliance affiliation (Stuart, Hoang, \& Hybels, 1999). Regardless of their status as active certifiers, partners can explore opportunities for interacting with other partners in a multipartner alliance (Gulati, 1995a; Gulati \& Gargiulo, 1999), which explains the insignificant market exposure benefits associated with product certification. These findings illustrate how partners that do not actively engage in product development can still benefit from their affiliation in multipartner alliances, thus revealing how the implications of internal involvement are contingent on the type of benefit.

More interesting, however, is the contingent value of internal involvement in an alliance board. Board members who sponsor a multipartner alliance generate common benefits from which other partners can gain (Khanna et al., 1998). For instance, all partners enjoy board members' efforts to achieve regulatory approval and promote the adoption of the multipartner alliance's technology. Our findings suggest that the market responds favorably to such involvement, but board members that seek to exert influence by investing excessive resources may not be able to improve their own productivity. We explain this deviation from the positive role ascribed to organizational involvement in dyadic alliances and some R\&D consortia (Dyer \& Singh, 1998; Gulati, Khanna, \& Nohria, 1994; Mothe \& Quelin, 2001; Saxton, 1997) as a trade-off in resource allocation decisions. Multipartner alliance board members direct most of their resources and attention to the achievement of common benefits, such as those emerging from creating an ecosystem and establishing a dominant design in competition against other multipartner alliances. These sponsorship activities may attenuate their self-interested, private product development efforts. We conclude that although strong internal involvement may prove essential for the overall success of a multipartner alliance and even enhance the market position and reputation of a partner, it does not necessarily provide private efficiency gains. This conclusion echoes previous research findings of disparity between partners' common and private benefits in dyadic alliances (Gulati et al., 1994; Kale et al., 2000; Khanna et al., 1998; Larsson et al., 1998). Under certain conditions, productivity losses may offset the marketing benefits that internal involvement furnishes. As the HomeRF Alliance illustrates, private losses may be exacerbated when a multipartner alliance loses in technology-driven competition. Therefore, whereas multipartner alliances may become useful for fostering industry-wide innovation efforts, enhancing compatibility, and creating public goods (Besen \& Johnson, 1986; David \& Greenstein, 1990; Farrell \& Saloner, 1985; Rosenkopf et al., 2001), the potential drawbacks for some partners may require deliberate managerial action to restrict losses on their part.

\section{The Implications of External Involvement in Multipartner Alliances}

The benefits that partners extract from affiliation in a multipartner alliance derive not only from their internal involvement in the alliance but also from their external engagement in competing multipartner alliances. Our study advances emerging research on competing alliance constellations (Gomes-Casseres, 1996, 2003; Lazzarini, 2007) by highlighting the benefits of simultaneous engagement in competing alliances. Our findings suggest that external involvement contributes to the productivity of partners, market acceptance of their products, and their overall reputations. Therefore, the hedging of investment options, reduced uncertainty, enhanced experience, and access to technical and market information, as well as the synergy derived from complementarity and interoperability of competing technologies, outweigh efficiency losses due to membership in competing multipartner alliances. Hence, one may wonder why only 26 percent of the Wi-Fi partners engaged in competing alliances. We posit that such multiple engagement poses managerial coordination challenges and entails a relational capability that evolves with partnering experience (Anand \& Khanna, 2000). Thus, the notion of relational capability should encompass not only specialization in managing dyadic alliances (Kale et al., 2002), but also the capacity to manage relationships within and across alliances.

The positive implications of external involvement also suggest that, besides gaining heterogeneous benefits in a successful multipartner alliance, some partners may extract benefits from a 
failing multipartner alliance to the extent that they maintain simultaneous or subsequent membership in a successful alliance. External involvement provides partners with the flexibility to adjust their investment in each alliance as uncertainty unfolds. Partners may enter an emerging industry by spreading their investments over competing multipartner alliances and, as a dominant design emerges, divert resources to the alliance that sponsors the dominant technology. For example, Intel was a founding member of the HomeRF Alliance but maintained regular membership in the Wi-Fi Alliance. Having witnessed the increasing dominance of the IEEE 802.11 standard, in September 2001 Intel became a board member in Wi-Fi and disassociated itself from HomeRF. In conclusion, external involvement in competing multipartner alliances offers important benefits but creates a challenge of managing trade-offs in alliance portfolios.

\section{Generalization and Directions for Future Research}

This study offers an explanation for the heterogeneity of benefits that multipartner alliance partners earn in technology-driven industries by examining the timing of entry into and organizational involvement in the Wi-Fi Alliance. Future research is needed to generalize our findings for different types of multipartner alliances in other industries. The Wi-Fi Alliance is a multipartner alliance that engaged in various value chain activities with a multilayered, semidemocratic governance structure and had voluntary entry and a large number of partners. In addition, this alliance faced technological and market uncertainty, competition from other multipartner alliances, and relative success in achieving its objectives. Our arguments and findings may be limited to these boundary conditions.

First, the Wi-Fi Alliance encompasses both R\&D and marketing activities. Other multipartner alliances may engage more intensively in basic research, as in R\&D consortia (Sakakibara \& Branstetter, 2003), or only in operations and marketing, as in alliance constellations in the airline industry (Lazzarini, 2007). The type of activity may influence coordination requirements, organizational complexity, and the benefits that multipartner alliances generate.

Second, a multipartner alliance's governance structure may range from an "ego network" that primarily benefits a focal sponsoring firm (e.g., Dyer \& Nobeoka, 2000) to a democratic collective with a predetermined payoff distribution scheme. Since the Wi-Fi Alliance adopted a semidemocratic governance structure that allows for discretionary behavior of partners, our findings are mostly applicable to multipartner alliances that foster stochastic heterogeneity of partner benefits. When a multipartner alliance lacks a hierarchical structure, internal involvement may be manifested in informal partner roles and clique structure, with weaker responsiveness and less coherent alliance decisions as a consequence. A nondemocratic multipartner alliance in turn may impose constraints on partners' internal involvement.

Third, if in contrast to membership in the Wi-Fi Alliance, multipartner alliance membership is exclusive and the entry of prospective partners can be declined, timing-of-entry decisions may be less relevant than they are here or at least may generate different patterns. For example, early entrants would be able to restrict subsequent entry and thus deter free riding. Future research might further examine the extent to which multipartner alliances can warrant a proportionate distribution of benefits to partners. Appropriability is especially difficult to regulate in informal multipartner alliances. In transaction cost economics (Williamson, 1975, 1979) the use of formal governance is advocated, whereas in the relational view (Dyer \& Singh, 1998; Zajac \& Olsen, 1993), the role of interorganizational trust and informal safeguards is acknowledged. Nevertheless, our study shifts attention from the role of alliance governance mechanisms (Reuer et al., 2002) to individual partners' timing-of-entry and organizational involvement decisions.

Fourth, our findings are most applicable to multipartner alliances that attract large numbers of partners. In smaller multipartner alliances, partners' actions are more easily observed, and formal governance may be redundant. Future research may study smaller multipartner alliances, wherein timing of entry may be less of an issue, while dyadic interactions, learning, and opportunistic behavior among partners substitute for organizational involvement in determining the distribution of alliance benefits.

Fifth, we studied alliance benefits in a technology-driven industry in which partners faced technological and market uncertainty. Our field interviews suggest that uncertainty about the success of the Wi-Fi Alliance cleared only in late 2004, a date beyond the time frame of our study. Technological uncertainty was not limited to the specification of the IEEE 802.11 standard, also encompassing interoperability and security issues that were critical for commercialization. Market uncertainty was ascribed to consumer adoption of wireless technologies and the availability of competing standards. Although the Wi-Fi Alliance was more successful than HiperLAN, HomeRF, and Bluetooth, it was not 
immune to the efforts of emerging contenders such as the WiMAX Alliance, initiated in 2002 to support the longer-range IEEE 802.16 and ETSI HiperMAN standards. Under such uncertainty, it is unlikely that partners will be able to predict their expected benefits and base entry and involvement decisions on performance expectations. This inability may explain partners' external involvement in competing multipartner alliances and the unexpected productivity losses of board members. Future research might examine partners' decisionmaking processes and their motivation for joining multipartner alliances in more detail. In particular, we expect that alleviated uncertainty would attenuate the merits of external involvement and allow prospective partners more discretion in deciding which multipartner alliance to join and when to enter it.

Sixth, although we assumed the prevalence of competing multipartner alliances, we do not expect our conclusions about internal involvement and timing of entry to change in the absence of competition among multipartner alliances unless regulatory intervention restricts the number of alliances in an industry. A multipartner alliance may still compete with individual firms that can outperform it, as illustrated in the case of Taligent, a joint venture formed by IBM, Apple, and Hewlett Packard, which failed to establish its CommonPoint application as a substitute for Microsoft's Windows. Future research could also study whether multipartner alliances emerge as a competitive response to a dominant firm in their industry and what leads firms to establish a new alliance instead of joining an existing one.

Finally, whereas the success of the Wi-Fi Alliance allowed us to effectively measure multipartner alliance benefits, it is possible that the dynamics of internal and external involvement and timing of entry differ in less successful alliances. Since failed multipartner alliances offer limited benefits to partners, it may be the case that the timing of exit is more critical than the timing of entry in these alliances. In addition, internal involvement may lead to private benefits more than to common benefits, with external involvement playing a more significant role. Thus, researchers may study heterogeneity in the distribution of losses to partners in unsuccessful alliances. Methodologically, to shed more light on the dynamics of entry and involvement decisions, future research might use in-depth field studies. Another opportunity for future research involves juxtaposition of intermultipartner alliance and intramultipartner alliance competition for alliance benefits in a given industry.

By examining the performance implications of organizational involvement and timing of entry, our study offers insights into the strategic behavior of partners in multipartner alliances with the aforementioned characteristics. It explains the heterogeneity of the benefits to partners and demonstrates how alliance affiliation is not necessarily beneficial to all partners. Our study paves the way for future research on multipartner alliances and offers guidance to firms that face the unique challenge of managing their participation in them.

\section{REFERENCES}

Allison, P. D. 1999. Logistic regression using the SAS system: Theory and application. Cary, NC: SAS Institute.

Anand, B. N., \& Khanna, T. 2000. Do firms learn to create value? The case of alliances. Strategic Management Journal, 21: 295-317.

Barron, D. N. 1992. The analysis of count data: Overdispersion and autocorrelation. Sociological Methodology, 22: 179-220.

Besen, S. M., \& Johnson, L. L. 1986. Compatibility standards, competition, and innovation in the broadcasting industry. Santa Monica, CA: Rand Corporation.

Chung, S., Singh, H., \& Lee, K. 2000. Complementarity, status similarity and social capital as drivers of alliance formation. Strategic Management Journal, 21: $1-22$.

Cohen, W. M., \& Levinthal, D. A. 1990. Absorptive capacity: A new perspective on learning and innovation. Administrative Science Quarterly, 35: 128152.

David, P. A., \& Greenstein, S. (Eds.). 1989. Compatibility standards and information technology-Business strategies, market development and public policies (publication number 159). Center for Economic Policy Research, Stanford University.

David, P. A., \& Greenstein, S. 1990. The economics of compatibility standards: An introduction to recent research. Economics of Innovation and New Technology, 1: 3-41.

Doz, Y. L. 1996. The evolution of cooperation in strategic alliances: Initial conditions or learning processes? Strategic Management Journal, 17(summer special issue): $55-84$.

Dutton, J. E. 1995. Strategic agenda building in organizations. In Z. Shapira (Ed.), Organizational decision making: 81-107. Cambridge, U.K.: Cambridge University Press.

Dyer, J. H., \& Nobeoka, K. 2000. Creating and managing a high-performance knowledge-sharing network: The Toyota case. Strategic Management Journal, 21: 345-367.

Dyer, J. H., \& Singh, H. 1998. The relational view: Coop- 
erative strategies and sources of interorganizational competitive advantage. Academy of Management Review, 23: 660-679.

Eisenhardt, K. M., \& Schoonhoven, C. B. 1996. Resourcebased view of strategic alliance formation: Strategic and social effects in entrepreneurial firms. Organization Science, 7: 136-150.

Farrell, J., \& Saloner, G. 1985. Standardization, compatibility, and innovation. Rand Journal of Economics, 16: $70-83$.

Farrell, J., \& Saloner, G. 1986a. Installed base and compatibility: Innovation, product preannouncements and predation. American Economic Review, 76: 940-955.

Farrell, J., \& Saloner, G. 1986b. Standardization and variety. Economics Letters, 20: 71-74.

Farrell, J., \& Saloner, G. 1988. Coordination through committees and markets. Rand Journal of Economics, 19: 235-252.

Gimeno, J. 2005. Competition within and between networks: The contingent effect of competitive embeddedness on alliance formation. Academy of Management Journal, 47: 820-842.

Gomes-Casseres, B. 1994. Group versus group: How alliance networks compete. Harvard Business Review, 72(4): 62-66.

Gomes-Casseres, B. 1996. The alliance revolution: The new shape of business rivalry. Cambridge, MA: Harvard University Press.

Gomes-Casseres, B. 2003. Competitive advantage in alliance constellations. Strategic Organization, 1: 327335.

Gomes-Casseres, B., \& Leonard-Barton, D. 1997. Alliance clusters in multimedia: Safety net or entanglement? In D. B. Yoffie (Ed.), Competition in the age of digital convergence: 325-369. Boston: Harvard Business School Press.

Granovetter, M. 1985. Economic action and social structure: The problem of embeddedness. American Journal of Sociology, 91: 481-510.

Gulati, R. 1995a. Does familiarity breed trust? The implications of repeated ties for contractual choices. Academy of Management Journal, 35: 85-112.

Gulati, R. 1995b. Social structure and alliance formation patterns: A longitudinal analysis. Administrative Science Quarterly, 40: 619-652.

Gulati, R. 1998. Alliances and networks. Strategic Management Journal, 19: 293-317.

Gulati, R., \& Gargiulo, M. 1999. Where do interorganizational networks come from? American Journal of Sociology, 104: 1439-1493.

Gulati, R., Khanna, T., \& Nohria, N. 1994. Unilateral commitments and the importance of process in alliances. Sloan Management Review, 35(3): 61.
Gulati, R., Nohria, N., \& Zaheer, A. 2000. Strategic networks. Strategic Management Journal, 21(special issue): 203-215.

Gulati, R., \& Wang, L. O. 2003. Size of the pie and share of the pie: Implications of structural embeddedness for value creation and value appropriation in joint ventures. Research in the Sociology of Organizations, 20: 209-242.

Hagedoorn, J. 1993. Understanding the rationale of strategic technology partnering. Strategic Management Journal, 14: 371-385.

Hagedoorn, J. 1995. Strategic technology partnering during the 1980s: Trends, networks, and corporate patterns in non-core technologies. Research Policy, 24: 207-231.

Hagedoorn, J., Link, A. N., \& Vonortas, N. S. 2000. Research partnerships. Research Policy, 29: 567-586.

Hall, B. H., Jaffe, A. B., \& Trajtenberg, M. 2001. The NBER patent citations data file: Lessons, insights and methodological tools (NBER working paper no. 8498). Cambridge, MA: National Bureau of Economics Research.

Hamel, G. 1991. Competition for competence and interpartner learning within international strategic alliances. Strategic Management Journal, 12(summer special issue): 83-103.

Hamilton, B. H., \& Nickerson, J. A. 2003. Correction for endogeneity in strategic management research. Strategic Organization, 1(1): 51-78.

Henderson, R. M., \& Clark, K. B. 1990. Architectural innovation: The reconfiguration of existing product technologies and the failure of established firms. Administrative Science Quarterly, 35: 9-30.

Hite, J. M., \& Hesterly, W. S. 2001. The evolution of firm networks: From emergence to early growth of the firm. Strategic Management Journal, 22: 275-286.

Huff, L. C., \& Robinson, W. T. 1994. Note: The impact of lead time and years of competitive rivalry on pioneer market share advantage. Management Science, 40: 1370-1377.

Jensen, M., \& Wang, D. 2003. Towards a sequence perspective on alliances: How alliance order and timing affect alliance outcome (working paper). Ann Arbor: University of Michigan.

Kale, P., Dyer, J. H., \& Singh, H. 2002. Alliance capability, stock market response, and long-term alliance success: The role of the alliance function. Strategic Management Journal, 23: 747-767.

Kale, P., Singh, H., \& Perlmutter, H. 2000. Learning and protection of proprietary assets in strategic alliances: Building relational capital. Strategic Management Journal, 21: 217-237.

Katz, M., \& Shapiro, C. 1985. Network externalities, competition and compatibility. American Economic Review, 28: 747-767. 
Katz, M., \& Shapiro, C. 1986. Technology adoption in the presence of network externalities. Journal of Political Economy, 94: 822-841.

Khanna, T. 1998. The scope of alliances. Organization Science, 9: 340-355.

Khanna, T., Gulati, R., \& Nohria, N. 1998. The dynamics of learning alliances: Competition, cooperation, and relative scope. Strategic Management Journal, 19: 193-210.

Kogut, B., \& Kulatilaka, N. 1993. Operating flexibility, global manufacturing, and the option value of a multinational network. Management Science, 39(11): 123-139.

Koh, J., \& Venkatraman, N. 1991. Joint venture formations and stock market reactions: An assessment in the information technology sector. Academy of Management Journal, 34: 869-892.

Lane, P. J., Salk, J. E., \& Lyles, M. A. 2001. Absorptive capacity, learning, and performance in international joint ventures. Strategic Management Journal, 22: 1139-1161.

Larsson, R., Bengtsson, L., Henriksson, K., \& Sparks, J. 1998. The interorganizational learning dilemma: Collective knowledge development in strategic alliances. Organization Science, 9: 285-305.

Lavie, D. 2004. The evolution and strategy of interconnected firms: A study of the Unisys alliance network. Paper presented at the 63rd Annual Meeting of the Academy of Management, New Orleans.

Lavie, D., \& Rosenkopf, L. 2006. Balancing exploration and exploitation in alliance formation. Academy of Management Journal, 49: 797-818.

Lazzarini, S. G. 2007. The impact of membership in competing alliance constellations: Evidence on the operational performance of global airlines. Strategic Management Journal, 28: 345-367.

Lieberman, M. B., \& Montgomery, D. B. 1988. First mover advantages. Strategic Management Journal, 9: 4158.

Lieberman, M. B., \& Montgomery, D. B. 1998. First mover (dis)advantages: Retrospective and link with the resource-based view. Strategic Management Journal, 19: 1111-1125.

Lorenzoni, G., \& Lipparini, A. 1999. The leveraging of interfirm relationships as a distinctive organizational capability: A longitudinal study. Strategic Management Journal, 20: 317-338.

Makadok, R. 1998. Can first-mover and early-mover advantages be sustained in an industry with low barriers to entry/imitation? Strategic Management Journal, 19: 683-696.

McConnell, J. J., \& Nantell, T. J. 1985. Corporate combinations and common stock returns: The case of joint ventures. Journal of Finance, 40: 519-536.

McGrath, R. G. 1997. A real options logic for initiating technology positioning investments. Academy of Management Review, 22: 974-996.

McGrath, R. G., \& Nerkar, A. 2004. Real options reasoning and a new look at the R\&D investment strategies of pharmaceutical firms. Strategic Management Journal, 25: 1-21.

Merchant, H., \& Schendel, D. 2000. How do international joint ventures create shareholder value? Strategic Management Journal, 21: 723-737.

Mitchell, W., Dussauge, P., \& Garrette, B. 2002. Alliances with competitors: How to combine and protect key resources? Creativity and Innovation Management, 11: 203-223.

Mothe, C., \& Quelin, B. V. 2001. Resource creation and partnership in R\&D consortia. Journal of High Technology Management Research, 12: 113-138.

Nohria, N., \& Garcia-Pont, C. 1991. Global strategic linkages and industry structure. Strategic Management Journal, 12: 105-124.

Ocasio, W. 1997. Towards an attention-based view of the firm. Strategic Management Journal, 18(summer special issue): 187-206.

Osborn, R. N., \& Hagedoorn, J. 1997. The institutionalization and evolutionary dynamics of interorganizational alliances and networks. Academy of Management Journal, 40: 261-278.

Park, S. H., \& Kim, D. 1997. Market valuation of joint ventures: Joint venture characteristics and wealth gains. Journal of Business Venturing, 12: 83-108.

Pfeffer, J., \& Salancik, G. R. 1978. The external control of organizations: $A$ resource dependence perspective. New York: Harper \& Row.

Powell, W. 1990. Neither market nor hierarchy: Network forms of organization. In B. M. Staw \& L. L. Cummings (Eds.), Research in organizational behavior, vol. 12: 295-336. Greenwich, CT: JAI Press.

Powell, W. W., Koput, K. W., \& Smith-Doerr, L. 1996. Interorganizational collaboration and the locus of innovation: Networks of learning in biotechnology. Administrative Science Quarterly, 41: 116-145.

Reuer, J. J., \& Koza, M. P. 2000. Asymmetric information and joint venture performance: Theory and evidence for domestic and international joint ventures. Strategic Management Journal, 21: 81-88.

Reuer, J. J., Zollo, M., \& Singh, H. 2002. Post-formation dynamics in strategic alliances. Strategic Management Journal, 23: 135-151.

Ring, P. S., \& Van De Ven, A. H. 1994. Developmental processes of co-operative interorganizational relationships. Academy of Management Review, 19: 90-118.

Rosenkopf, L., Metiu, A., \& George, V. P. 2001. From the bottom up? Technical committee activity and alliance formation. Administrative Science Quarterly, 46: $748-772$. 
Rowley, T., Behrens, D., \& Krackhardt, D. 2000. Redundant governance structures: An analysis of structural and relational embeddedness in the steel and semiconductor industries. Strategic Management Journal, 21: 369-386.

Rowlinson, M. 2001. The politics and economics of power. Journal of Management Studies, 38(5): 762765.

Rumelt, R. P. 1974. Strategy, structure, and economic performance. Cambridge, MA: Harvard University Press.

Sakakibara, M. 1997. Heterogeneity of firm capabilities and cooperative research and development: An empirical examination of motives. Strategic Management Journal, 18(summer special issue): 143-164.

Sakakibara, M. 2001. Cooperative research and development: Who participates and in which industries do projects take place? Research Policy, 30: 993-1018.

Sakakibara, M. 2002. Formation of R\&D consortia: Industry and company effects. Strategic Management Journal, 23: 1033-1050.

Sakakibara, M. 2003. Knowledge sharing in cooperative research and development. Managerial and Decision Economics, 24: 117-132.

Sakakibara, M., \& Branstetter, L. 2003. Measuring the impact of US research consortia. Managerial and Decision Economics, 24: 51-69.

Saxton, T. 1997. The effects of partner and relationship characteristics on alliance outcomes. Academy of Management Journal, 40: 443-461.

Shapiro, C., \& Varian, H. R. 1998. Information rules: $A$ strategic guide for the network economy. Boston: Harvard Business School Press.

Siegel, D. S. 2003. Data requirements for assessing private and social returns to strategic research partnerships: Analysis and recommendations. Technology Analysis \& Strategic Management, 15(2): 207-225.

Silverman, B. S., \& Baum, J. A. C. 2002. Alliance-based competitive dynamics. Academy of Management Journal, 45: 791-806.

Stuart, T. 1998. Network positions and propensities to collaborate: An investigation of strategic alliance formation in a high-technology industry. Administrative Science Quarterly, 43: 668-698.

Stuart, T., Hoang, H., \& Hybels, R. 1999. Interorganizational endorsements and the performance of entrepreneurial ventures. Administrative Science Quarterly, 44: 315-349.

Teece, D. J. 1986. Profiting from technological innovations: Implications for integration, collaboration, li- censing, and public policy. Research Policy, 15: 285-303.

Tsai, W., \& Ghoshal, S. 1998. Social capital and value creation: The role of intrafirm networks. Academy of Management Journal, 41: 464-476.

Tushman, M. L., \& Anderson, P. 1986. Technological discontinuities and organizational environments. Administrative Science Quarterly, 31: 439-465.

Tushman, M. L., \& Rosenkopf, L. 1992. On the organizational determinants of technological change: Toward a sociology of technological evolution. In B. M. Staw \& L. L. Cummings (Eds.), Research in organizational behavior, vol. 14: 311-347. Greenwich, CT: JAI Press.

Utterback, J. 1987. Innovation and industrial evolution in manufacturing industries. In B. Guile \& H. Brooks (Eds.), Technology and global industry: Companies and nations in the world economy: 16-48. Washington, DC: National Academy Press.

Uzzi, B. 1996. The sources and consequences of embeddedness for the economic performance of organizations: The network effect. American Sociological Review, 61: 674-698.

Uzzi, B. 1997. Social structure and competition in interfirm networks: The paradox of embeddedness. Administrative Science Quarterly, 42: 35-67.

Vanhaverbeke, W., \& Noorderhaven, N. G. 2001. Competition between alliance blocks: The case of the RISC microprocessor technology. Organization Studies, 22: $1-30$.

Vuong, Q. H. 1989. Likelihood ratio tests for model selection and non-nested hypotheses. Econometrica, 57: 307-333.

Williamson, O. E. 1975. Markets and hierarchies, analysis and antitrust implications: $A$ study in the economics of internal organization. New York: Free Press.

Williamson, O. E. 1979. Transaction-cost economics: The governance of contractual relations. Journal of Law and Economics, 22: 233-261.

Yin, X., \& Wu, J. 2003. Where do multiple-partner alliances come from? Theory and evidence in industry-sponsored e-marketplaces. Paper presented at the 23rd Annual International Conference of the Strategic Management Society, Baltimore.

Zajac, E. J., \& Olsen, C. P. 1993. From transaction cost to transaction value analysis: implications for the study of interorganizational strategies. Journal of Management Studies, 30: 131-145.

Zollo, M., Reuer, J. J., \& Singh, H. 2002. Interorganizational routines and performance in strategic alliances. Organization Science, 13: 701-713. 


\section{APPENDIX A}

\section{Descriptive Statistics of Wi-Fi Partners and Products in June 2003}

(A1) Accumulated Number of Certified Wi-Fi Products

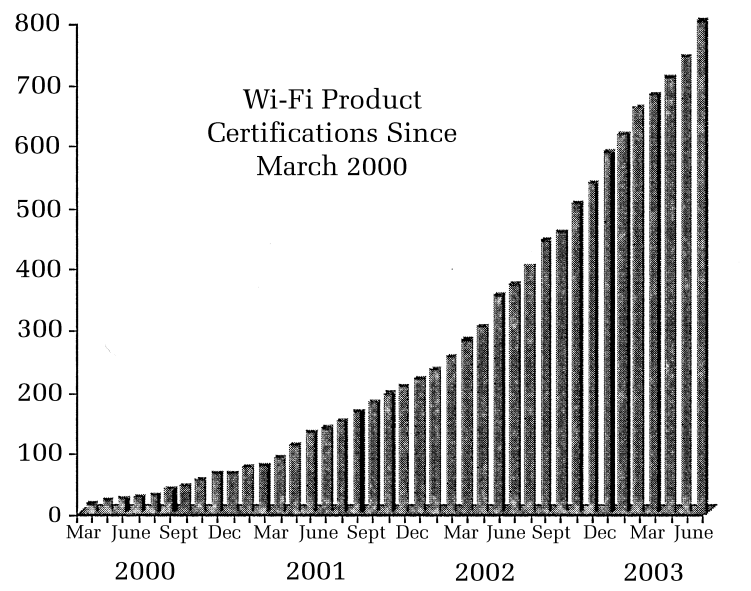

(A3) Accumulated Number of Partners Joining Wi-Fi
(A2) Number of Certified Wi-Fi Products by Category

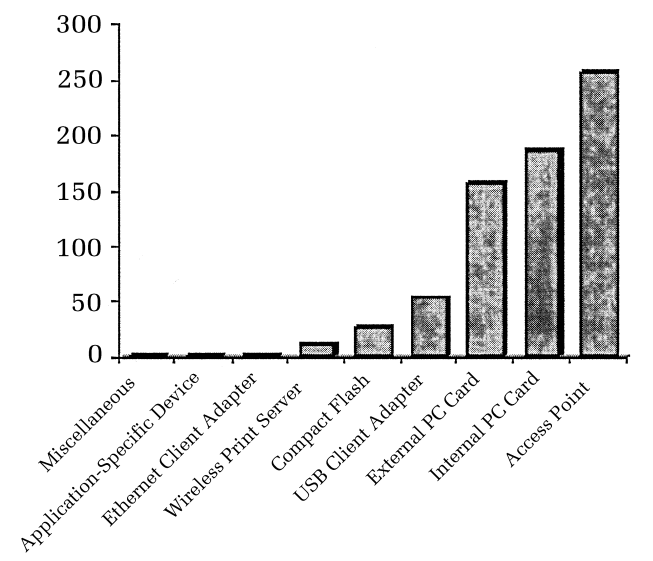

(A4) Number of Wi-Fi Partners by Industry-Two-Digit SIC

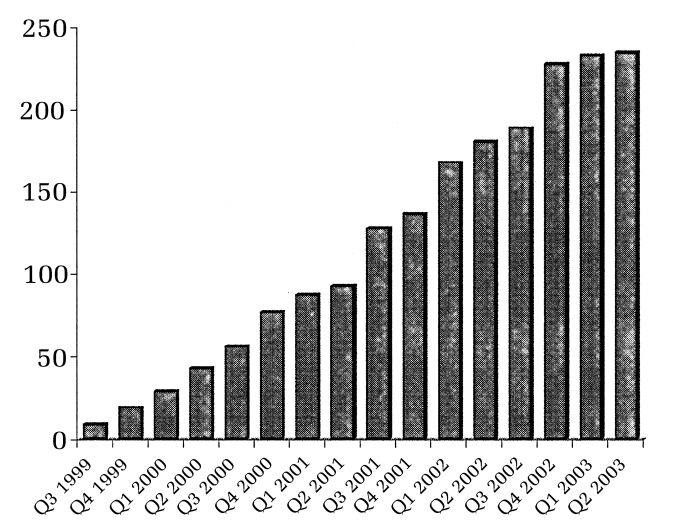

APPENDIX B

\section{Robustness Tests}

To test the robustness of our findings, we examined alternative operationalizations and models. We first considered alternative measures for our dependent variables but had to rule them out because of data availability constraints. For example, we could not measure partners' revenues from certified products because partners do not typically report these figures, especially for products recently released to market or serving as components in integrated systems. Overall partner profitability and stock market performance were also unavailable for most private firms (59.2 percent of our sample) and did not reflect relevant financial returns for partners such as IBM and Microsoft that were not focused Wi-Fi product developers. Finally, we gathered market share data for the worldwide WLAN market using the extensive Gartner report, which covers the top 20 firms that together account for 85 percent of the market. Despite limited coverage in terms of the number of firms, market share was positively correlated with our number of certified products and market success measures ( $r=.70$ and .75 , respectively, $p<.001$ ).

In addition, we considered alternative measures for our independent variables. For example, we computed an alternative measure of timing of entry based on the elapsed calendar time between partners' dates of entry and the date of alliance formation. Our results were robust to the use of this alternative measure, which was highly correlated $(r=.99, p<.001)$ with our reported measure based on the order of entry. We also examined the total number of delegates that partners sent to the IEEE 802.11 working group sessions as an indicator of internal involvement. This measure was highly correlated with board membership $(r=.66, p<$ .001 ) and produced consistent effects on alliance benefits. We retained our reported measures because they better reflected internal involvement in the Wi-Fi Alliance.

We also considered alternative operationalizations of our control variables. For instance, we classified partners on the basis of their business descriptions as equipment components, infrastructure, network products, peripheral products, service, or software firms 
(relying on the databases Factiva, Mergent, Gale, and Dun \& Bradstreet); however, we preferred the SIC classification, since the effects of this alternative control were insignificant. We then considered a more general diversity measure based on patent counts by primary patent class indicated in the USPTO databases, for which we applied the 36 technological subcategory classification of Hall, Jaffe, and Trajtenberg (2001). When added as a control variable, this measure produced no significant effects, but our specific diversity measure persistently produced significant positive effects. For this reason, we retained only the more specific measure and concluded that our findings reflected the advantages of establishing broad product market reach rather than pursuing unrelated diversification to different technological fields. We even considered an alternative measure of innovativeness based on patent counts in the more specific domain of the IEEE 802.11 standard; this produced similar results to those reported for our original measure.

In auxiliary analyses, we examined additional controls, such as a partner's country of origin, value of assets, net revenues, number of employees, solvency, and R\&D intensity. These data were extracted from COMPUSTAT for publicly traded firms and from Dun \& Bradstreet for private firms but were mostly available for the publicly traded partners and turned out insignificant. After verifying that their inclusion did not materially change the parameter estimates of our main effects, we omitted these controls to avoid severe reduction in degrees of freedom owing to missing values. Our sensitivity tests revealed, for instance, that the overall pattern of results was not supportive of a partner size effect. Perhaps controls for partner size based on net revenues or number of employees were less relevant in this context because the Wi-Fi Alliance assigned one vote per partner firm rather than one vote per engineer. In addition, large corporations do not necessarily dominate product development in emerging technology industries (Tushman \& Anderson, 1986). Finally, our robustness tests revealed that despite the positive correlations between productivity, market success, and market exposure (see Table 1), our findings were consistent when we included alternative alliance benefits measures as controls.

To study the boundary conditions of our theory, we tested additional curvilinear and interaction effects in auxiliary analyses in which we used data plots to corroborate our interpretations. For example, we examined the hazards of overinvolvement in competing alliances by adding a quadratic term of external involvement; it did not affect market success or market exposure but produced a negative effect on productivity $(\beta=-0.33, p<.05)$. Since this effect was insignificant in the subsample of active certifiers, we ascribed it to the fact that some members of competing alliances might have joined the Wi-Fi Alliance to monitor it and access information rather than to actively engage in the certification of Wi-Fi products. In the same vein, we tested an interaction term of external involvement and internal involvement through board membership. In keeping with our field interviews, we found a negative interaction effect on partners' market success $(\beta=$ $-1.28, p<.05$ ), which could be ascribed to the expectation that board members should be fully committed to promoting Wi-Fi as their primary WLAN technology. Next, we introduced an interaction term between timing of entry and external involvement, which produced a positive effect on market success $(\beta=0.06$, $p<.05)$. Thus, partners leveraged their experience in competing multipartner alliances to successfully develop, introduce, and market Wi-Fi-related products, despite their late entry to the Wi-Fi Alliance. In addition, we found positive interaction effects of partners' timing of entry and R\&D investments on market success $(\beta=0.03, p<.05)$ and market exposure $(\beta=0.02$, $p<.05)$. Although $\mathrm{R} \& \mathrm{D}$ data were available only for 34 percent of the partners, these findings suggested that late entry was more beneficial to partners that could more effectively leverage the collective knowledge of incumbent partners in the multipartner alliance.

Finally, we considered the possibility that despite the uncertainty that limited partners' capacity to form performance expectations, endogeneity of internal and external involvement decisions ${ }^{a}$ and potential omission of control variables biased our results. We first examined additional controls for partners' organizational capabilities using proxies such as R\&D investment, which was highly correlated with our existing product diversity control $(r=.68, p<.001)$. The inclusion of these controls did not substantially affect our results but reduced the effective sample size because of missing values. Following Hamilton and Nickerson (2003), we next constructed two-stage models with correction for endogeneity. In the first-stage models, we instrumented internal and external involvement on the remaining independent and control variables reported in Tables 2 and 3 . In addition, we included predictors such as partner size, partner country of origin, and partner business classification (equipment components, infrastructure, network products, peripheral products, service, or software). The first-stage models' fit (measured as pseudo- $R^{2}$ ) reached .64 for board membership, .24 for active certification, and .39 for external involvement in competing alliances. We incorporated the Mills ratios from the first stage as controls in the second-stage models. The control variable correcting for endogeneity of active certification produced no significant effect, and the control for endogeneity of external involvement was insignificant in all but the productivity model $(\beta=-0.42, p<$ $.05)$, in which our main effects remained significant. Finally, the control for endogeneity of board membership was significant in the market success $(\beta=-0.23$, $p<.001)$ and market exposure models $(\beta=-0.04, p<$

\footnotetext{
${ }^{\text {a }}$ Partners could not consider timing of entry in their decisions to join the Wi-Fi Alliance since timing of entry depends on the subsequent decisions of later entrants. Nevertheless, partners may be influenced by earlier entrants.
} 
.05). Nevertheless, our main effects in the market exposure model remained significant, whereas in the market success model, all but one effect remained significant. It is possible, however, that the lower signif- icance level resulted from loss of degrees of freedom owing to the missing values in the first stage. Overall, the consistency of the results of the two-stage models attenuates concerns of endogeneity or omitted variable bias.
Dovev Lavie (dovev.lavie@mccombs.utexas.edu) is an assistant professor of management at the University of Texas at Austin and a Sloan Industry Studies fellow. He is also a Landau fellow supported by the Taub Foundation and a senior lecturer at the Technion. He received his Ph.D. from the Wharton School of the University of Pennsylvania. His current research interests include value creation and appropriation in alliance networks and applications of the resource-based view and the dynamic capabilities approach in technology-intensive industries.

Christoph Lechner (christoph.lechner@unisg.ch) is the EMBA Professor of Strategic Management and the director of the Institute of Management at the University of St. Gallen (Switzerland). He received his Ph.D. and habilitation from the University of St. Gallen. His current research interests are in the area of strategy process and alliance and network strategy.

Harbir Singh (singhh@wharton.upenn.edu) is the William and Phyllis Mack Professor of Management at the Wharton School, the University of Pennsylvania. He is also codirector of Wharton's Mack Center for Technological Innovation. He received his Ph.D. from the University of Michigan. His research focuses on corporate development via acquisitions, alliances, and restructuring. 